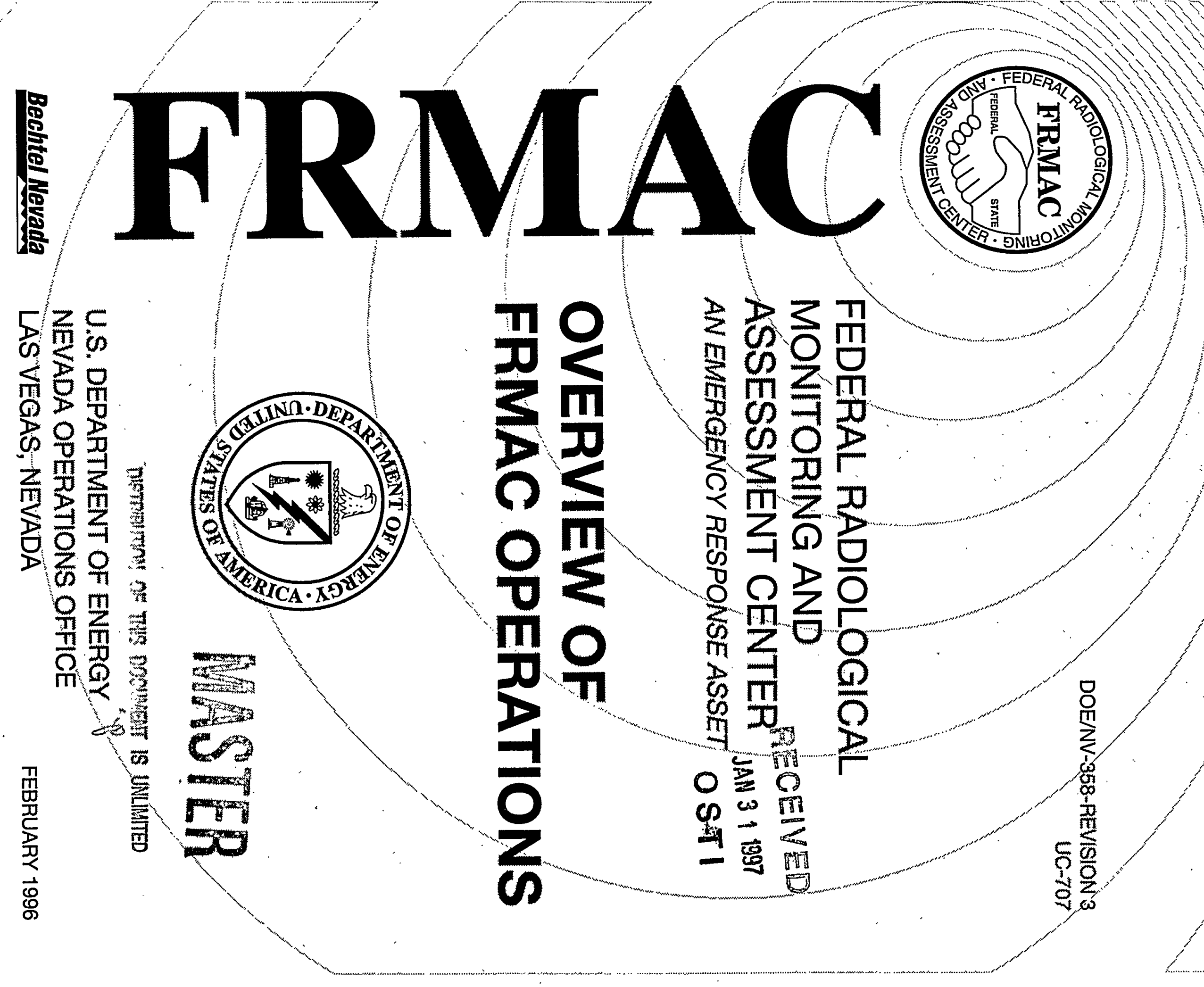




\section{DISCLAIMER}

This report was prepared as an account of work sponsored by an agency of the United States government. Neither the United States government nor any agency thereof, nor any of their employees, makes any warranty, express or implied, or assumes any legal liability or responsibility for the accuracy, completeness, or usefulness of any information, apparatus, product, or process disclosed or represents that its use would not infringe privately owned rights. Reference herein to any specific commercial product, process, or service by trade name, trademark, manufacturer, or otherwise, does not necessarily constitute or imply its endorsement, recommendation, or favoring by the United States government or any agency thereof. The views and opinions of authors expressed herein do not necessarily state or reflect those of the United States government or any agency thereof.

This report has been reproduced directly from the best available copy.

This report is available to DOE and DOE contractors from the Office of Scientific and Technical Information, P.O. Box 62, Oak Ridge, Tennessee 37831. Call (615) 576-8401 to obtain prices.

This report is available to the public from the National Technical Information Service, U.S. Department of Commerce, 5285 Port Royal, Springfield, Virginia 22161. 


\title{
FEDERAL RADIOLOGICAL MONITORING AND ASSESSMENT CENTER (FRMAC) OVERVIEW OF FRMAC OPERATIONS
}

\author{
Prepared By \\ Remote Sensing Laboratory \\ Operated by \\ Bechtel Nevada
}

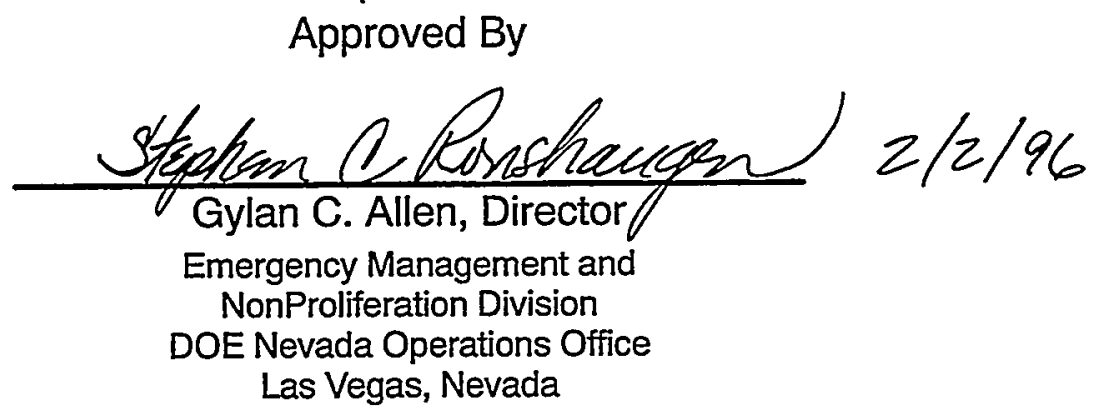

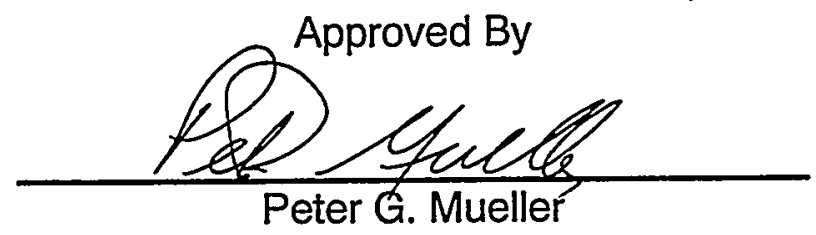

FRMAC Program Manager

Emergency Management and

NonProliferation Division

DOE Nevada Operations Office

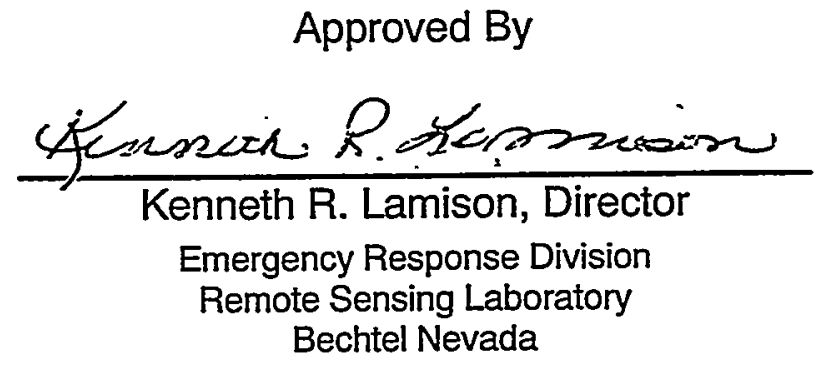

Approved By

This Document is UNCLASSIFIED

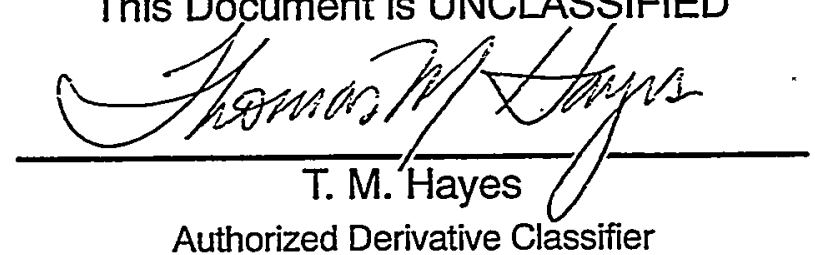

Bechtel Nevada

This work was performed for the United States Department of Energy by Bechtal Nevada under Contract Number DE-AC08-96NV11718 and by EG\&G/EM under Contract Number DE-AC08-93NV11265. 


\section{DISCLAIMIER}

Portions of this document may be illegible in electronic image products. Images are produced from the best available original document. 


\section{PREFACE}

The Federal Emergency Management Agency issued a Federal Radiological Emergency Response Plan as a Federal Register notice on November 8, 1985. A proposed revision was issued September 15,1995 . The Federal Radiological Emergency Response Plan states that the federal agencies with statutory responsibilities for emergencies involving radioactive materials have agreed to coordinate their emergency response efforts. In the event of a significant radiological emergency, a Federal Radiological Monitoring and Assessment Center would be established close to the emergency site to provide technical federal assistance to the Lead Federal Agency responsible for the regulation and/or operation of the accident site and to the impacted state(s). The primary mission of the Federal Radiological Monitoring and Assessment Center is to manage and coordinate federal off-site radiological monitoring and assessment activities.

Since 1986 the Federal Radiological Emergency Response Plan has undergone some changes. This overview document reflects the most recent changes included in the proposed version, dated September 15, 1995.

This document is an overview of the FRMAC Operations Plan, Emergency Phase. It will be revised (as appropriate) with the reissuance of revised federal guidance, changes in agency responsibilities, or as a result of experience gained through exercises and training. Revision 3 includes operational and organizational changes due to revisions of the FRMAC Operations Plan. 


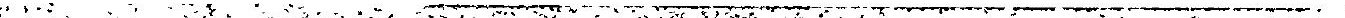




\section{CONTENTS}

Preface

\section{Sections}

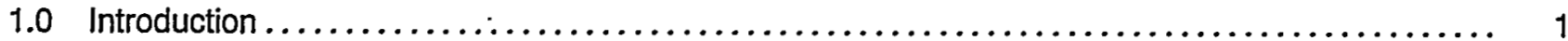

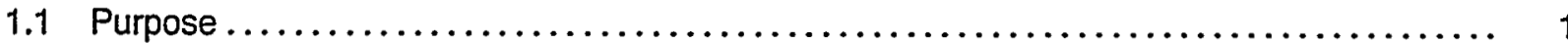

1.2 Federal Radiological Emergency Response Plan (FRERP) $\ldots \ldots \ldots \ldots \ldots \ldots \ldots \ldots \ldots$

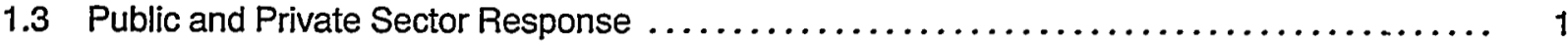

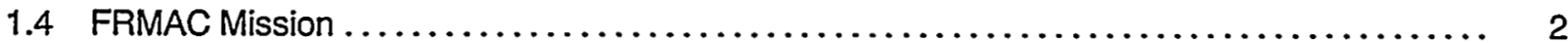

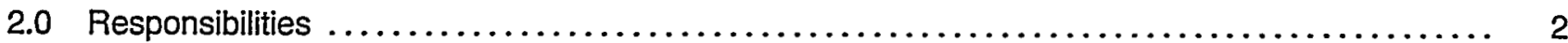

2.1 Lead Federal Agency (LFA) $\ldots \ldots \ldots \ldots \ldots \ldots \ldots \ldots \ldots \ldots \ldots \ldots \ldots \ldots \ldots \ldots \ldots \ldots \ldots \ldots, 2$

2.2 Federal Emergency Management Agency (FEMA) $\ldots \ldots \ldots \ldots \ldots \ldots \ldots \ldots \ldots \ldots \ldots \ldots$

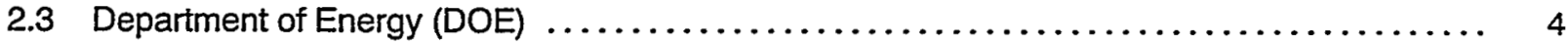

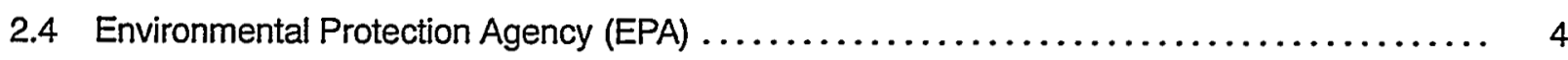

2.5 State and Local Authorities ........................................... 4

2.6 Advisory Team for Environment, Food, and Health (Advisory Team) ................ 4

2.7 Other Federal Agencies ............................................. 5

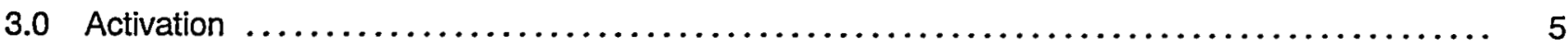

3.1 Description of the Emergency ........................................ 5

3.2 Call-Up Procedures/Authorities ....................................... 5

3.3 Radiological Assistance Program (RAP) Response $\ldots \ldots \ldots \ldots \ldots \ldots \ldots \ldots \ldots \ldots . \ldots \ldots$

3.4 FRMAC Activation Stages and Timelines .................................. 7

3.4.1 FRMAC Advance Party ........................................... 7

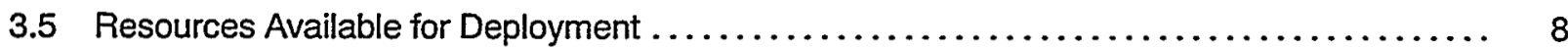

3.5.1 Atmospheric Release Advisory Capability (ARAC) $\ldots \ldots \ldots \ldots \ldots \ldots \ldots \ldots . \ldots$

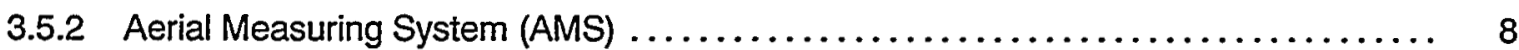

3.5.3 Radiation Emergency Assistance Center/Training Site (REAC/TS) ............. 8

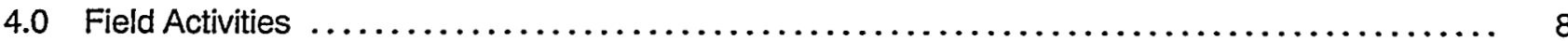

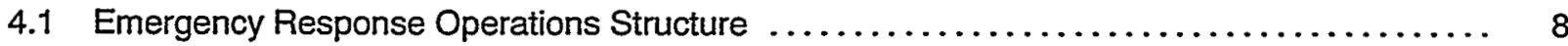

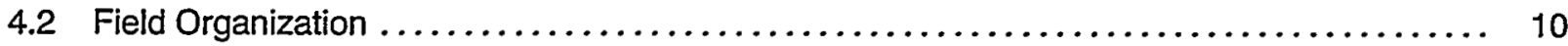

4.3 Information Flow and Priorities .......................................... 10

4.4 Interfacing $\ldots \ldots \ldots \ldots \ldots \ldots \ldots \ldots \ldots \ldots \ldots \ldots \ldots \ldots \ldots \ldots \ldots \ldots \ldots \ldots \ldots \ldots \ldots \ldots \ldots, 11$

4.4.1 Department of Energy (DOE) $\ldots \ldots \ldots \ldots \ldots \ldots \ldots \ldots \ldots \ldots \ldots \ldots \ldots \ldots \ldots \ldots \ldots \ldots \ldots, 11$ 


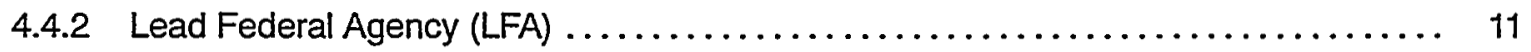

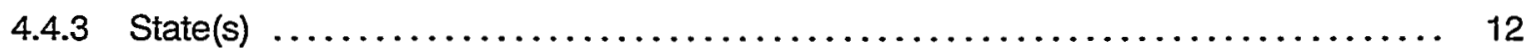

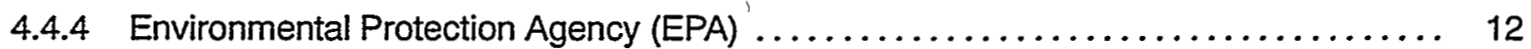

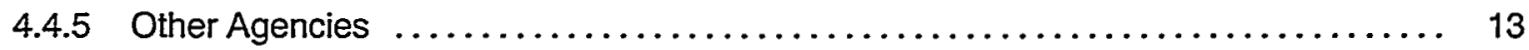

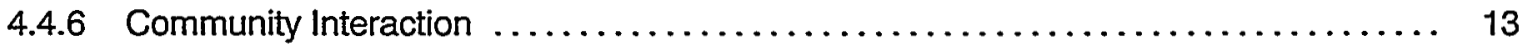

\section{Figures}

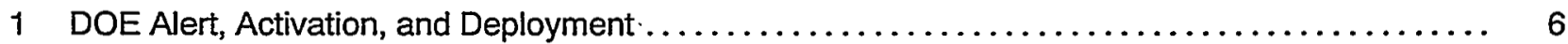

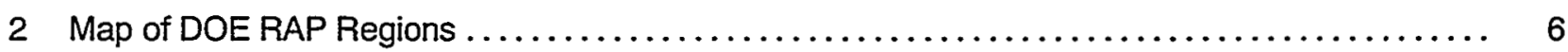

3 Approximate Arrival Times for Various DOE Assets After Authority to Activate $\ldots \ldots \ldots \ldots \ldots \ldots$. 7

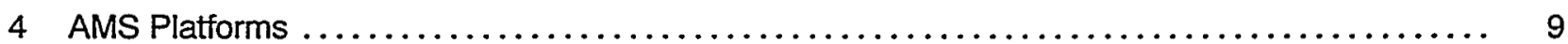

5 FRMAC Response Operational Structure $\ldots \ldots \ldots \ldots \ldots \ldots \ldots \ldots \ldots \ldots \ldots \ldots \ldots \ldots \ldots \ldots \ldots \ldots \ldots \ldots$

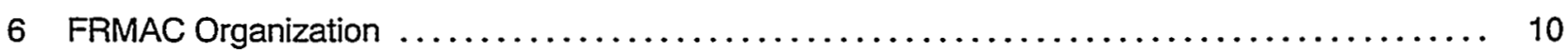

7 FRMAC Radiological Data Information Flow $\ldots \ldots \ldots \ldots \ldots \ldots \ldots \ldots \ldots \ldots \ldots \ldots \ldots \ldots \ldots \ldots \ldots \ldots \ldots$

8 Exercise Interactions with State Representatives $\ldots \ldots \ldots \ldots \ldots \ldots \ldots \ldots \ldots \ldots \ldots \ldots \ldots \ldots$

C-1 Typical Aerial Radiological Survey Setup $\ldots \ldots \ldots \ldots \ldots \ldots \ldots \ldots \ldots \ldots \ldots \ldots \ldots \ldots \ldots \ldots$

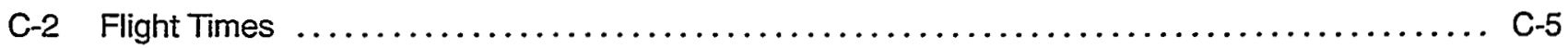

\section{Tables}

1 Identification of Lead Federal Agencies for Radiological Emergencies $\ldots \ldots \ldots \ldots \ldots \ldots \ldots$

C-1 AMS Minimum Detectable Activities . . . . . . . . . .

\section{Appendices}

A Federal Agency Signatories to the Federal Radiological Emergency

Response Plan (FRERP)

B Federal Radiological Monitoring and Assessment Center (FRMAC)

Data Output Products

B.1 Plume Dispersion and Dose Projections $\ldots \ldots \ldots \ldots \ldots \ldots \ldots \ldots \ldots \ldots \ldots \ldots \ldots \ldots \ldots \ldots \ldots$

B.2 Aerial Survey Data $\ldots \ldots \ldots \ldots \ldots \ldots \ldots \ldots \ldots \ldots \ldots \ldots \ldots \ldots \ldots \ldots \ldots \ldots \ldots \ldots \ldots \ldots \ldots$

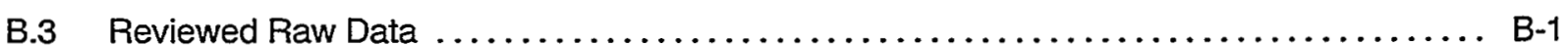




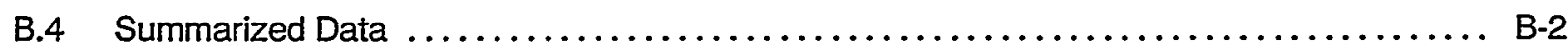

B.5 Exposure Rate and/or Contamination Contours $\ldots \ldots \ldots \ldots \ldots \ldots \ldots \ldots \ldots \ldots \ldots \ldots$ B-2

B.6 Dose Projections from Actual Measurements $\ldots \ldots \ldots \ldots \ldots \ldots \ldots \ldots \ldots \ldots \ldots \ldots \ldots \ldots \ldots$

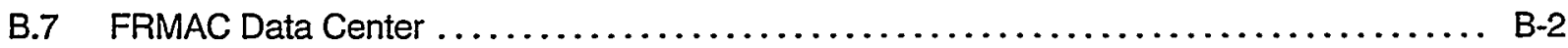

B.8 Geographic Information System (GIS) Products $\ldots \ldots \ldots \ldots \ldots \ldots \ldots \ldots \ldots \ldots \ldots$ B-3

B.9 Tailored Format for Users $\ldots \ldots \ldots \ldots \ldots \ldots \ldots \ldots \ldots \ldots \ldots \ldots \ldots \ldots \ldots \ldots \ldots \ldots \ldots \ldots \ldots \ldots$

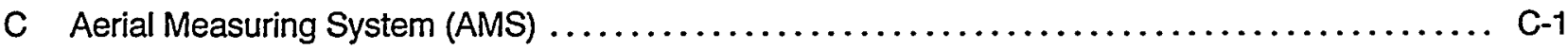

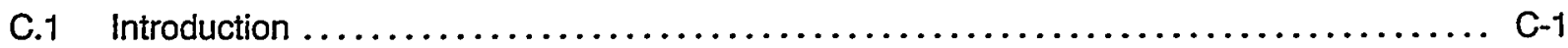

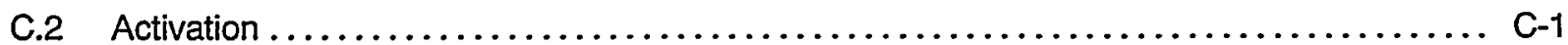

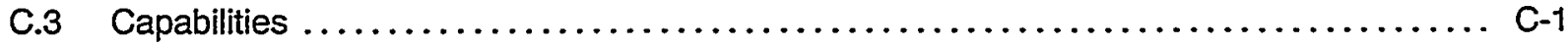

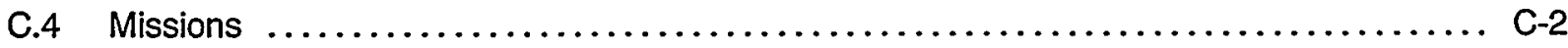

C.5 Aerial Radiological Survey Sensitivities $\ldots \ldots \ldots \ldots \ldots \ldots \ldots \ldots \ldots \ldots \ldots \ldots \ldots \ldots \ldots \ldots$

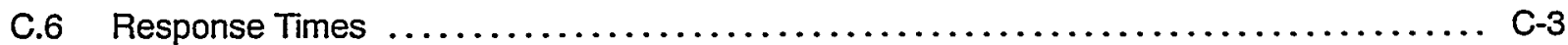

Federal Radiological Monitoring and Assessment Center (FRMAC)
Site Selection Considerations $\ldots \ldots \ldots \ldots \ldots \ldots \ldots \ldots \ldots \ldots \ldots \ldots \ldots \ldots \ldots \ldots \ldots \ldots \ldots \ldots$

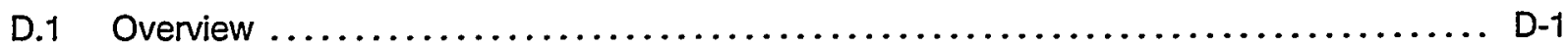

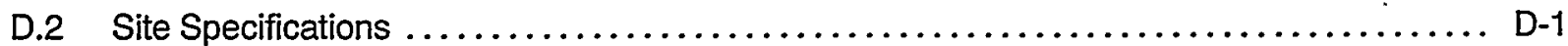

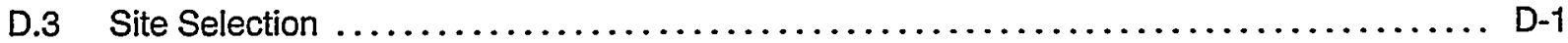

E Federal Radiological Monitoring and Assessment Center (FRMAC)

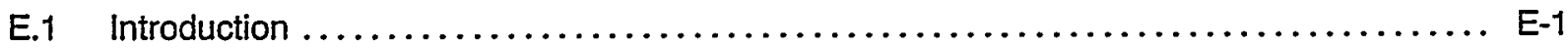

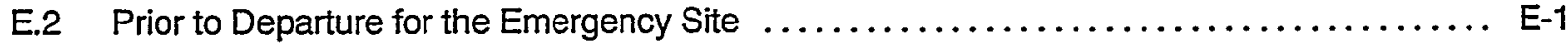

E.3 Upon Arrival On-Scene $\ldots \ldots \ldots \ldots \ldots \ldots \ldots \ldots \ldots \ldots \ldots \ldots \ldots \ldots \ldots \ldots \ldots \ldots \ldots \ldots \ldots \ldots \ldots$

E.4 Advance Party Meeting Agenda $\ldots \ldots \ldots \ldots \ldots \ldots \ldots \ldots \ldots \ldots \ldots \ldots \ldots \ldots \ldots \ldots \ldots \ldots \ldots$

F Federal Radiological Monitoring and Assessment Center (FRMAC)

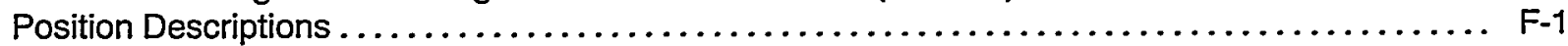

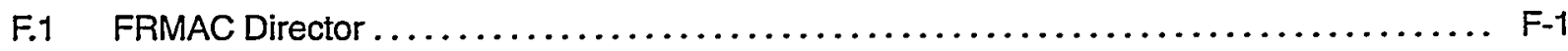

F.2 Deputy FRMAC Director $\ldots \ldots \ldots \ldots \ldots \ldots \ldots \ldots \ldots \ldots \ldots \ldots \ldots \ldots \ldots \ldots \ldots \ldots \ldots \ldots \ldots \ldots \ldots$

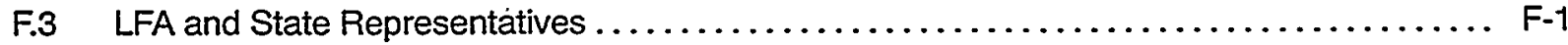

F.4 Environmental Protection Agency (EPA) Senior Official $\ldots \ldots \ldots \ldots \ldots \ldots \ldots \ldots \ldots \ldots$ F-1 


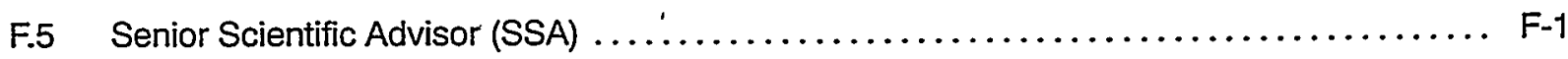

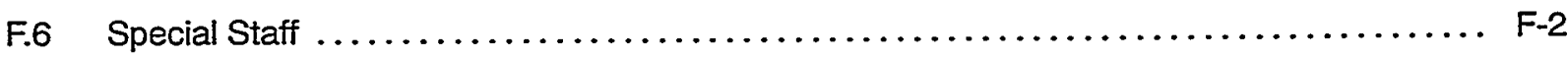

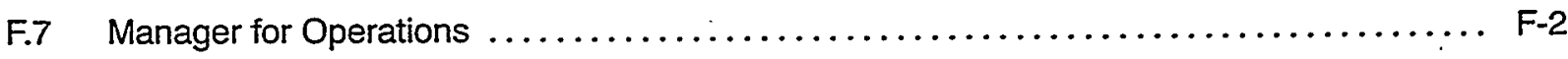

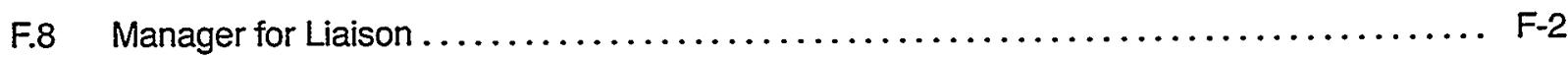

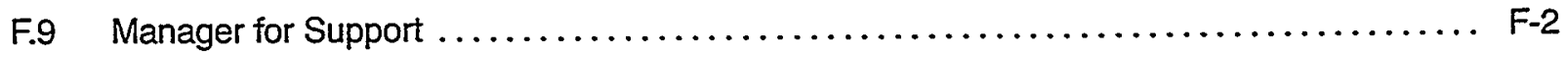

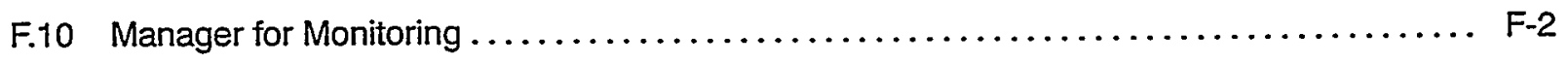

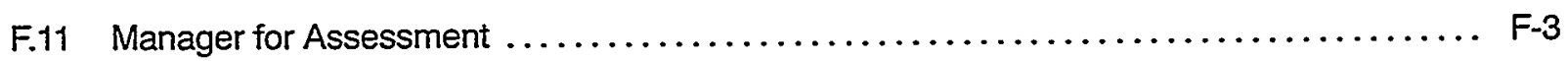

F.12 Manager for FRMAC Health and Safety $\ldots \ldots \ldots \ldots \ldots \ldots \ldots \ldots \ldots \ldots \ldots \ldots \ldots \ldots \ldots \ldots \ldots \ldots \ldots$

F.13 Other Key Personnel in the FRMAC Facilities $\ldots \ldots \ldots \ldots \ldots \ldots \ldots \ldots \ldots \ldots \ldots \ldots \ldots \ldots \ldots \ldots \ldots \ldots$

F.13.1 Representatives from other Agencies to the FRMAC $\ldots \ldots \ldots \ldots \ldots \ldots \ldots \ldots$ F-3

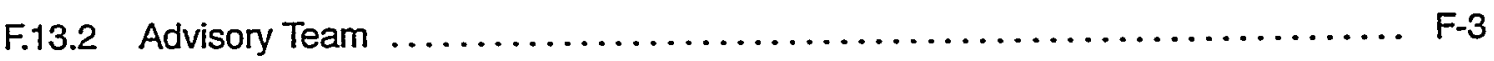

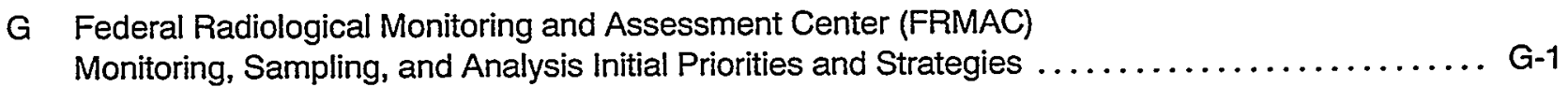

G.1 Advance Party Meeting $\ldots \ldots \ldots \ldots \ldots \ldots \ldots \ldots \ldots \ldots \ldots \ldots \ldots \ldots \ldots \ldots \ldots \ldots \ldots \ldots \ldots \ldots \ldots$

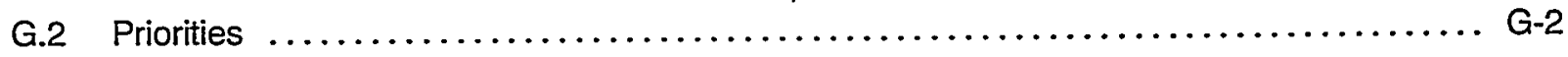

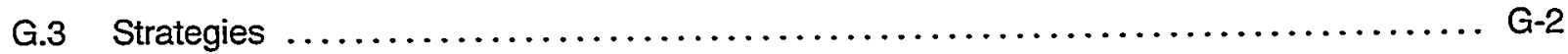

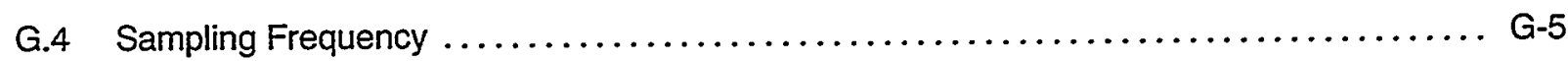

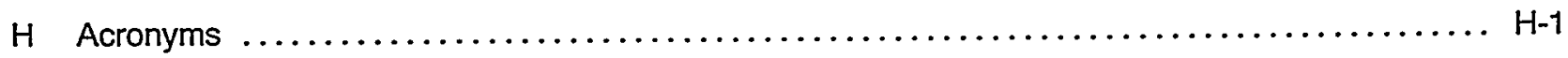




\subsection{INTRODUCTION}

\subsection{Purpose}

In the event of a major radiological emergency, 17 federal agencies with various statutory responsibilities have agreed to coordinate their efforts at the emergency scene under the umbrella of the Federal Radiological Emergency Response Plan (FRERP). These agencies are listed in Appendix A. This cooperative effort will assure the designated Lead Federal Agency (LFA) and the state(s) that all federal radiological assistance fully supports their efforts to protect the public. The mandated federal cooperation ensures that each agency can obtain the data critical to its specific responsibilities.

This Overview of the Federal Radiological Monitoring and Assessment Center (FRMAC) Operations describes the FRMAC response activities to a major radiological emergency. ${ }^{1}$ It also describes the federal assets and subsequent operational activities which provide federal radiological monitoring and assessment of the off-site areas. ${ }^{2}$ These off-site areas may include one or more affected states.

\subsection{Federal Radiological Emergency Response Plan (FRERP)}

The FRERP ensures that any federal involvement or response to a radiological emergency will be managed, coordinated, organized, and integrated. The FRERP covers any emergency that has, or is expected to have, an off-site radiological impact within the United States, its territories, reservations, possessions, or territorial waters and which could require a response by the federal government.

The FRERP describes actions and responsibilities by which federal, state, and local agencies can most effectively integrate their operations. The degree to which the federal response is merged or activities are adjusted will be based on the requirements and priorities set by the LFA and the state(s). The FRERP will be implemented when requested by the LFA or by the state. The FRERP assigns to DOE and FRMAC the responsibilities to provide federal off-site monitoring and assessment results to the LFA and the state(s).

\subsection{Public and Private Sector Response}

State, tribal, county, and/or city governments have primary responsibility for determining and implementing measures to protect health, safety, property, and the environment in all areas outside the boundaries of a fixed nuclear facility or those not under the control of a federal agency. The owner or operator of a nuclear facility has primary responsibility for actions within the boundaries of that facility; for providing notification and advice to off-site state, local, and tribal officials; and for minimizing the radiological hazard to the public.

For emergencies involving an area under federal control, the responsibility for on-site actions belongs to the federal government while off-site actions are the responsibility of the state, tribal, and/or local governments. For all other emergencies, the state, tribal, and/or local government has the responsibility for taking emergency actions, both on-site and off-site.

\footnotetext{
1 The term "radiological emergency" is used throughout this report. It is applicable to an accident, an incident, a potential accident, or a potential, perceived, or deliberate act to spread radioactivity in the environment.

2 The FRERP refers to the "on-site" area as the area inside the fence line or property line of the facility which is experiencing the emergency or if a nuclear weapon is involved, inside a federal government-defined National Defense Area or National Security Area. "Off-site” applies to all other areas.
} 
Because the assignment of specific responsibilities for protecting the public varies from state to state and tribal, county, and city interests are involved as well, this overview employs the term "local authorities" to generically address, the local group in the public sector (including tribal) that has radiological protection responsibilities for the public.

\subsection{FRMAC Mission}

A FRMAC is established in response to the LFA or state request when a major radiological emergency is anticipated or has occurred. The FRMAC becomes a coalition of all federal off-site monitoring and assessment efforts to assist the LFA, state(s), and local authorities. State and local agencies are invited to collocate and prioritize work efforts in the FRMAC.

A FRMAC provides an operational framework for coordinating all federal off-site radiological monitoring and assessment activities during a response to a radiological emergency to support the LFA and state(s) in a timely manner. This support will include:

1. Providing FRMAC liaisons with the LFA, state(s), and local authorities.

2. Gathering radiological information and data that will include:

- Plume and deposition predictions, as appropriate.

- Air and ground concentrations.

- Deposition patterns of isotopic concentrations, exposure rates, and dose projections.

- Isotopic concentrations.

- Assurance of data quality.

- Current meteorological conditions and weather forecasts.

3. Providing the results of data collection, sample analysis, evaluations, assessments, and interpretations to the LFA and appropriate state, federal, and local agencies, as requested. Generic FRMAC products are given in Appendix $B$.

4. Compiling a complete database containing all off-site radiological monitoring and sampling data.

5. Providing technical assistance to the LFA, state(s), and local authorities to the extent resources are available.

\subsection{RESPONSIBILITIES}

The management responsibilities for a federal radiological emergency response are divided among several agencies and organizations. These responsibilities are discussed below.

\subsection{Lead Federal Agency (LFA)}

The LFA is the agency which has responsibility for all aspects of the federal response. The LFA is defined as the federal agency that owns, authorizes, regulates, or is otherwise deemed responsible for the facility or radiological activity causing the emergency and has authority to take action on-site. The designation of LFAs is summarized in Table 1.

The LFA will:

1. Coordinate the overall activities (both on-site and off-site) of all federal agencies during all phases of a radiological emergency response. 


\section{Table 1. Identification of Lead Federal Agencies for Radiological Emergencies}

\begin{tabular}{|c|c|}
\hline Type of Emergency & $\begin{array}{l}\text { Lead Federal } \\
\text { Agency }\end{array}$ \\
\hline \multicolumn{2}{|l|}{ 1. Nuclear Facility } \\
\hline A. Licensed by NRC or an agreement state ${ }^{a}$ & NRC \\
\hline B. Owned or Operated by DoD or DOE & DOD or DOE \\
\hline $\begin{array}{l}\text { C. Not licensed, owned, or operated by a federal agency or an } \\
\text { agreement state }\end{array}$ & EPA \\
\hline \multicolumn{2}{|l|}{ 2. Transport of Radioactive Materials } \\
\hline $\begin{array}{l}\text { A. Shipment of materials licensed by NRC or an agreement } \\
\text { state }\end{array}$ & NRC \\
\hline B. Materials shipped by or for DoD or DOE & DOD or DOE \\
\hline $\begin{array}{l}\text { C. Shipment of materials not licensed or owned by a federal } \\
\text { agency or an agreement state }\end{array}$ & EPA \\
\hline 3. Domestic Satellites Containing Radioactive Materials & NASA or DoD \\
\hline 4. Impact from Foreign or Unknown Source & $\begin{array}{l}\text { EPA, DoD, or } \\
\text { NASA }\end{array}$ \\
\hline 5. Other Types of Emergencies & LFAs Confer \\
\hline
\end{tabular}

a An agreement state is a state that has agreements with the Nuclear Regulatory Commission (NRC) to license and have regulatory authority over nuclear materiais in their state.

2. Oversee on-site response and support operator activities.

3. Assist state(s) and local authorities in determining appropriate measures to protect the public, property, and the environment.

4. Coordinate and provide all federal Protective Action Recommendations (PARs) to the state(s) and local authorities.

5. Ensure that federal agencies assist state(s) and local authorities in implementing protective actions, if requested.

6. Serve as the principal federal source of information for on-site conditions; coordinate all public information on federal response activities; and provide information to Congress, the White House, and the Department of State (when foreign countries are affected).

7. Establish on-scene response centers.

- The Joint Operations Center (JOC) is the coordination center for the overall federal response

- The Joint Information Center (JIC) coordinates information to the public and media.

\subsection{Federal Emergency Management Agency (FEMA)}

The Senior FEMA Official (SFO) will coordinate the overall nonradiological federal off-site support to the LFA, state(s), and local authorities. The general responsibilities of the SFO and the FEMA Emergency Response Team are to: 
1. Manage the Disaster Field Office (DFO) which coordinates all nonradiological federal resource support provided to the state and local authorities.

2. Promote coordination among federal agencies with the state(s) and local authorities concerning interactions on nonradiological issues.

3. Serve as the coordinator for information related to the federal nonradiological response.

\subsection{Department of Energy (DOE)}

The FRERP assigns to DOE the responsibility for establishing and initially managing the FRMAC.

Under the FRERP, when a FRMAC is activated, DOE's responsibilities are to:

1. Provide technical support to the LFA, state(s), and local authorities by establishing the FRMAC and coordinating the off-site federal radiological monitoring, assessment, and evaluation of data.

2. Provide various operational assets including radiation detection and measurement equipment, communications support, and aerial monitoring capability, as appropriate.

3. Following the initial phase of the emergency, provide off-site support to the Environmental Protection Agency (EPA) when it assumes management of the FRMAC.

DOE Headquarters (DOE/HQ) has assigned the responsibility for FRMAC to the DOE Nevada Operations Office (DOE/NV) in Las Vegas, Nevada. This office provides day-to-day management; development of FRMAC plans, procedures and exercise coordination; as well as oversight of working groups.

\subsection{Environmental Protection Agency (EPA)}

The EPA provides a Senior Official to the FRMAC to assist in the operation of the FRMAC as an EPA representative. EPA will also be represented on the Advisory Team for Environment, Food, and Health which supports the LFA.

At a mutually agreeable time, the DOE in coordination with the LFA, EPA, and the state(s) will transfer FRMAC management responsibilities to the EPA. The EPA will assume the federal agency responsibility for coordinating the intermediate and long-term off-site radiological monitoring, sampling, and assessment activities. When this occurs, DOE and other federal agencies will continue to commit the equipment, personnel, and funds for the duration of the federal response effort as necessary.

\subsection{State and Local Authorities}

State and local authorities are responsible for the health and welfare of the general public during an emergency. They will assess the situation and issue instructions for necessary protective actions. The state receives federal PARs from the LFA which serves as the federal channel for such recommendations.

\subsection{Advisory Team for Environment, Food, and Health (Advisory Team)}

The LFA will be assisted by the Advisory Team composed of the EPA and the U.S. Department of Agriculture (USDA) and the Health and Human Services (HHS) representatives and supported by other 
federal agencies as needed. This team will use all available radiological data and assessments to assist the LFA in developing federal PARs. The Advisory Team will work with the LFA to request FRMAC monitoring and assessment results and provide input to priorities.

The Advisory Team provides direct support to the LFA and has no independent authority. The Advisory Team will not release information or make recommendations to the public unless authorized to do so by the LFA.

The Advisory Team is anticipated to collocate with the FRMAC to have easy access to FRMAC data and assessments and to accommodate the needs of the LFA and state(s). FRMAC groups will work closely with the Advisory Team, as needed and as requested by the LFA.

\subsection{Other Federal Agencies}

All other federal agencies, not previously identified as having a management and/or support role, will respond in accordance with the FRERP at the request of FEMA, the LFA, DOE, or the impacted state(s) or in accordance with established statutory responsibilities.

\subsection{ACTIVATION}

\subsection{Description of the Emergency}

When the DOE is formally notified of a radiological emergency and a FRMAC is requested, DOE will obtain a description, as detailed as possible, of the emergency. To ensure a timely and appropriate response, the following information will be requested:

1. The nature and condition of the emergency (i.c., is a release eminent, in process, or has it already occurred?).

2. The type of facility or radiological material involved in the emergency (e.g., a power reactor, nuclear material, etc.).

3. The location of the emergency and the nearest major city or town.

4. An estimate of the source term and isotope(s) involved and the chemical and physical form, if known.

5. The name and telephone number of a technical person from the reporting organization who is knowledgeable of the radiological situation.

6. The extent of knowledge about the release and distribution.

7. Public protective actions initiated.

8. The meteorological conditions at the time of the emergency.

9. If the request is not from state authorities, has the state been notified and do they agree with the decision to deploy the FRMAC?

\subsection{Call-Up Procedures/Authorities}

At the request of the LFA and/or state, DOE/HQ will authorize the activation and deployment of FRMAC and contractors which support the FRMAC (see Figure 1). The primary DOE assets supporting the FRMAC are the Radiological Assistance Program (RAP), the Atmospheric Release Advisory 
Capability (ARAC), the Aerial Measuring System (AMS), and the Radiation Emergency Assistance Center/Training Site (REAC/TS) teams.

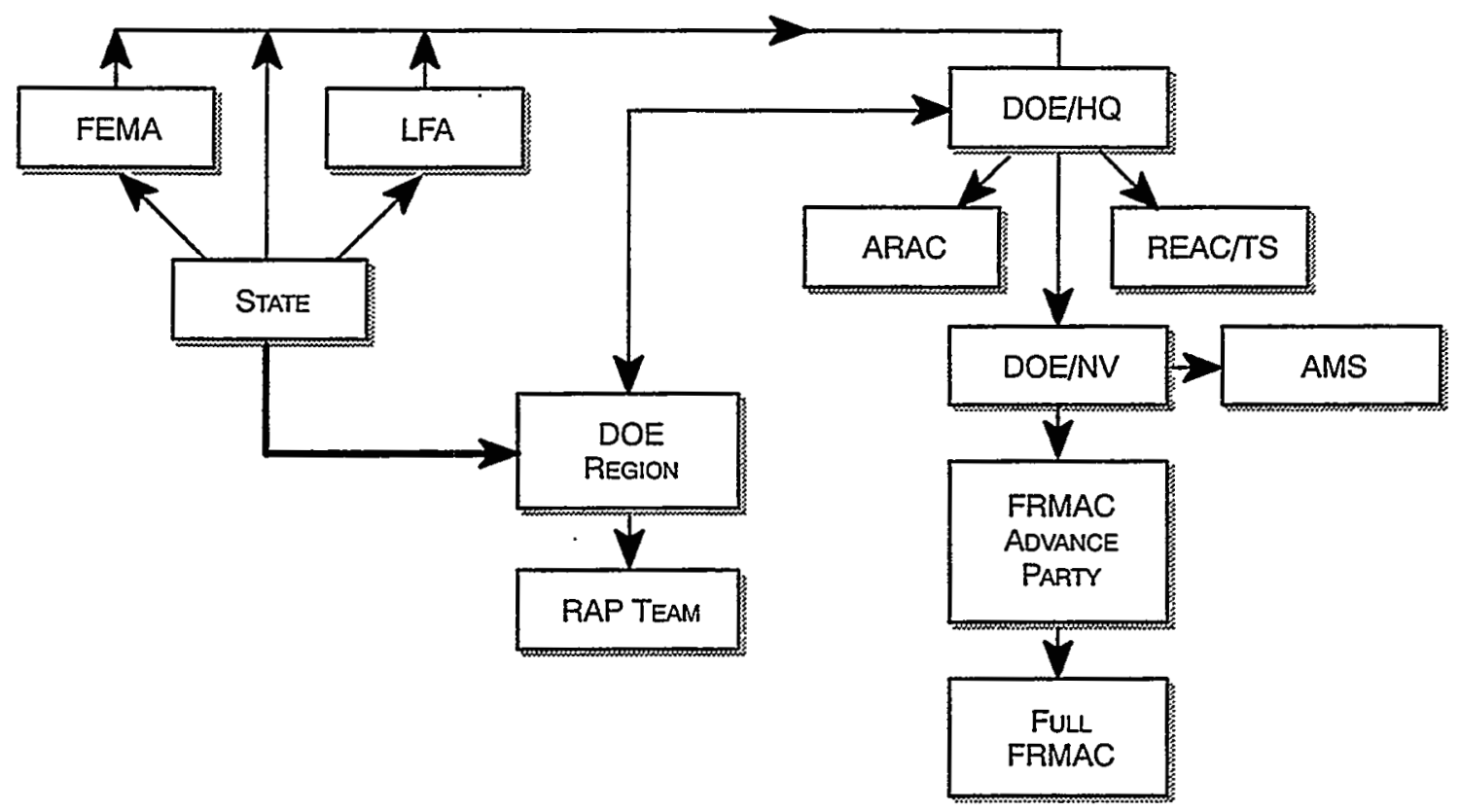

FIGURE 1. DOE ALERT, ACTIVATION, AND DEPLOYMENT

\subsection{Radiological Assistance Program (RAP) Response}

Each of the eight DOE Regional Coordinating Offices (see Figure 2) maintains a 24-hour response capability for radiological emergencies which may occur in states served by their region. The RAP Teams can be expected to be on-scene within two to six hours after notification. These teams are equipped with monitoring equipment and protective clothing and can provide a significant early assessment of the radiological situation.

RAP REGIONAL COORDINATING OFFICES

1. Brookhaven, NY

(516)344-2200

2. Oak Ridge, TN

(423) 576-1005

3. Savannah River, SC ..

(803) $725-3333$

4. Albuquerque, NM

(505) 845-4667

5. Chicago, IL

(708) 252-4800

6. Idaho Falls, ID

(208) 526-1515

7. Oakland, CA

(510) $637-1794$

8. Richland, WA

. (509) 373-3800

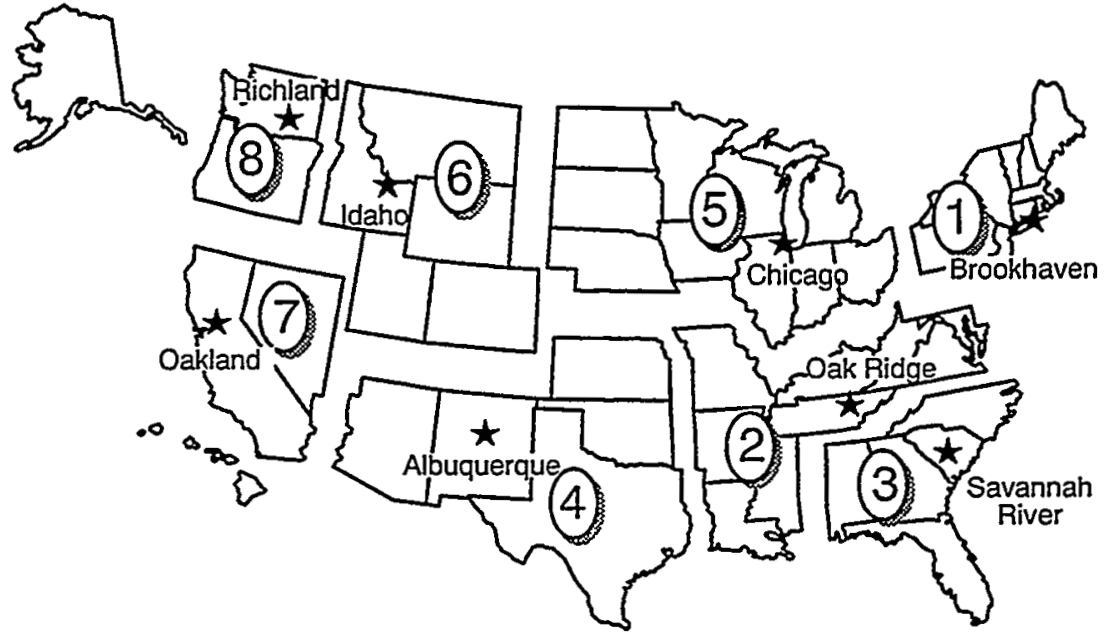

FIGURE 2. MAP OF DOE RAP REGIONS 


\subsection{FRMAC Activation Stages and Timelines}

When notified that a FRMAC response is required, the manager of DOE/NV, with concurrence of DOE/HQ, designates a FRMAC Director and initiates FRMAC deployment. A FRMAC Advance Party can be expected to arrive at the emergency site within four to eight hours after notification. The full FRMAC will be established within 24 to 36 hours. The FRMAC will function as a self-sufficient facility designed to augment, rather than burden, local resources. Figure 3 identifies the approximate arrival times of various DOE assets.

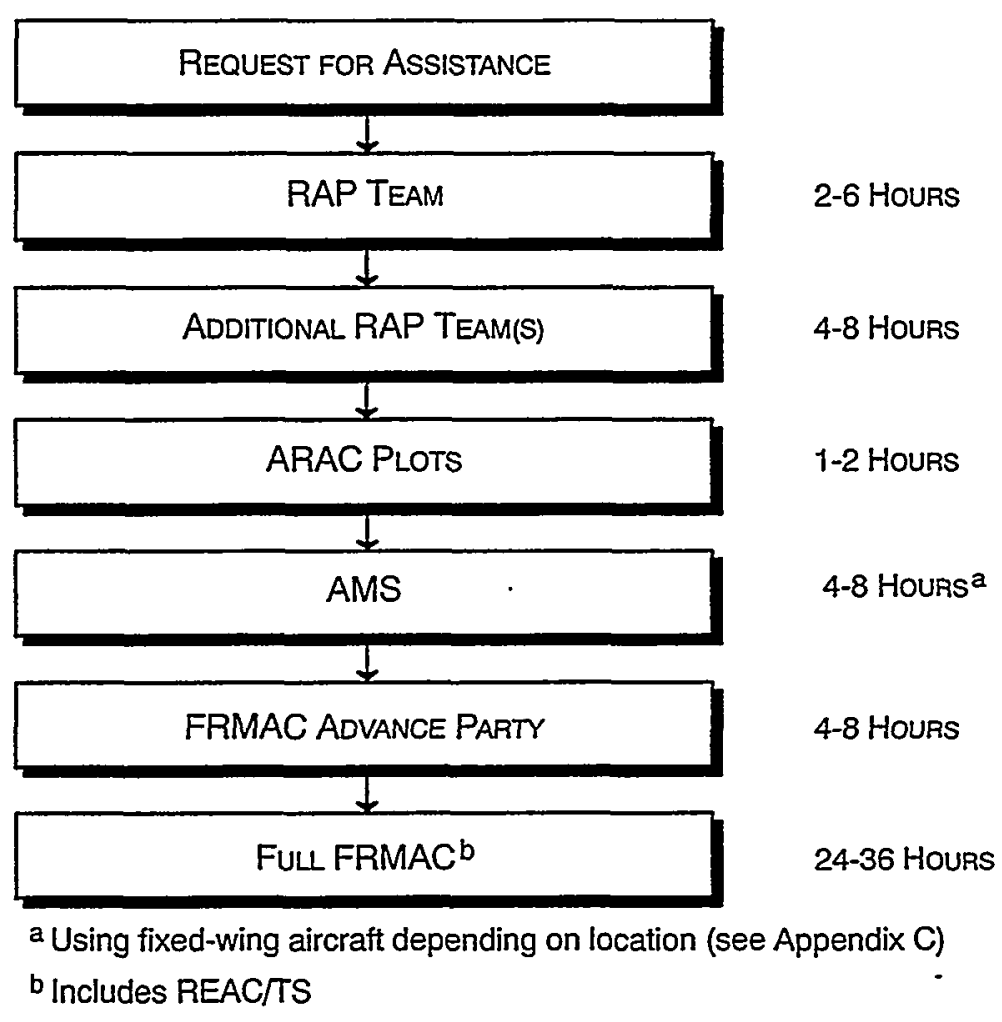

FIGURE 3. APPROXIMATE ARRIVAL TIMES FOR VARIOUS DOE ASSETS AFTER AUTHORITY TO ACTIVATE

\subsubsection{FRMAC Advance Party}

After receiving notification to deploy, the FRMAC Advance Party will arrive at the emergency location within four to eight hours. The Advance Party may consist of 6 to 20 key personnel. They will meet with the LFA and the state(s), determine their requirements, define the appropriate level and composition of a FRMAC response and locate a suitable site for an operational FRMAC. FRMAC site-selection criteria is discussed in Appendix D. The size of the FRMAC Main Party is dependent upon the magnitude of the emergency.

During this meeting, members of the Advance Party will obtain the status of the emergency, public protective actions which have been initiated, available monitoring data, and any other pertinent information. In addition, FRMAC, LFA, and state liaisons will be identified and the initial FRMAC Monitoring and Sampling Plan will be developed. This plan will reflect the state and LFA requirements and emphasize public safety. FRMAC Advance Party issues are given in Appendix E. 


\subsection{Resources Available for Deployment}

DOE and EPA provide significant radiation monitoring, analysis, and assessment equipment as well as highly skilled professionals. In addition, the DOE FRMAC team provides the essential communications, photo/video, computer network, and mechanical/electrical support. The total amount of equipment needed may require several C-141 aircraft. Both institutional and mobile laboratories are available from DOE, EPA, and other federal agencies. FRMAC may provide equipment and/or personnel to state, county, or local Emergency Operations Centers (EOCs) to augment communication processes with the FRMAC, as requested. The following DOE assets will be activated and deployed, depending upon the real or potential impact of the emergency.

\subsubsection{Atmospheric Release Advisory Capability (ARAC)}

The ARAC at Lawrence Livermore National Laboratory in California produces calculated contour plots of air concentration, airborne dose, ground deposition, or ground exposure rates overlaid on a map of the emergency area. ARAC can be activated through the RAP team, the DOE Regional Coordinating Office, or DOE/HQ.

ARAC results aid in (1) assessing downwind areas receiving significant radiation dose and deposition, (2) the deployment of field teams, and (3) AMS survey plans.

\subsubsection{Aerial Measuring System (AMS)}

The AMS helicopter and fixed-wing aircraft, operated for DOE by the Remote Sensing Laboratory (RSL) (see Figure 4), are equipped to measure radioactive material deposited on the ground and to perform plume tracking and sampling. The aircraft, permanently based at Andrews Air Force Base (AFB) near Washington, D.C., and at Nellis AFB in Las Vegas, Nevada, are key elements of a response to an emergency involving dispersal of radioactive material over a large area.

The DOE AMS program has an extensive collection of background radiologic and photographic surveys of nuclear facilities in the United States. These survey results can be used as a baseline for evaluating releases of radioactivity from an accident or incident at one of the sites. A more detailed discussion of the AMS capabilities is given in Appendix $C$. The aerial response can occur in the same time frame as the FRMAC Advance Party deployment.

\subsubsection{Radiation Emergency Assistance Center/Training Site (REAC/TS)}

The REAC/TS, located in Oak Ridge, Tennessee, provides direct support through deployable medical and health physics professionals. This team of medical experts specializes in the care and treatment of victims of radiation exposure and other types of physical injuries. The REAC/TS team provides support to the FRMAC workers and advice to other emergency centers as requested by the LFA and the state(s).

\subsection{FIELD ACTIVITIES}

\subsection{Emergency Response Operations Structure}

The emergency response structure, as related to FRMAC, is shown in Figure 5. FRMAC operations support the LFA and state. Other key functions, which may be located in the FRMAC facilities, contribute to, but are not a part of, FRMAC operations. These include the Advisory Team and other agency state and local representatives of other agencies, as needed. Figure 5 depicts information flow of requests for, and results of, radiological data and assessments. 


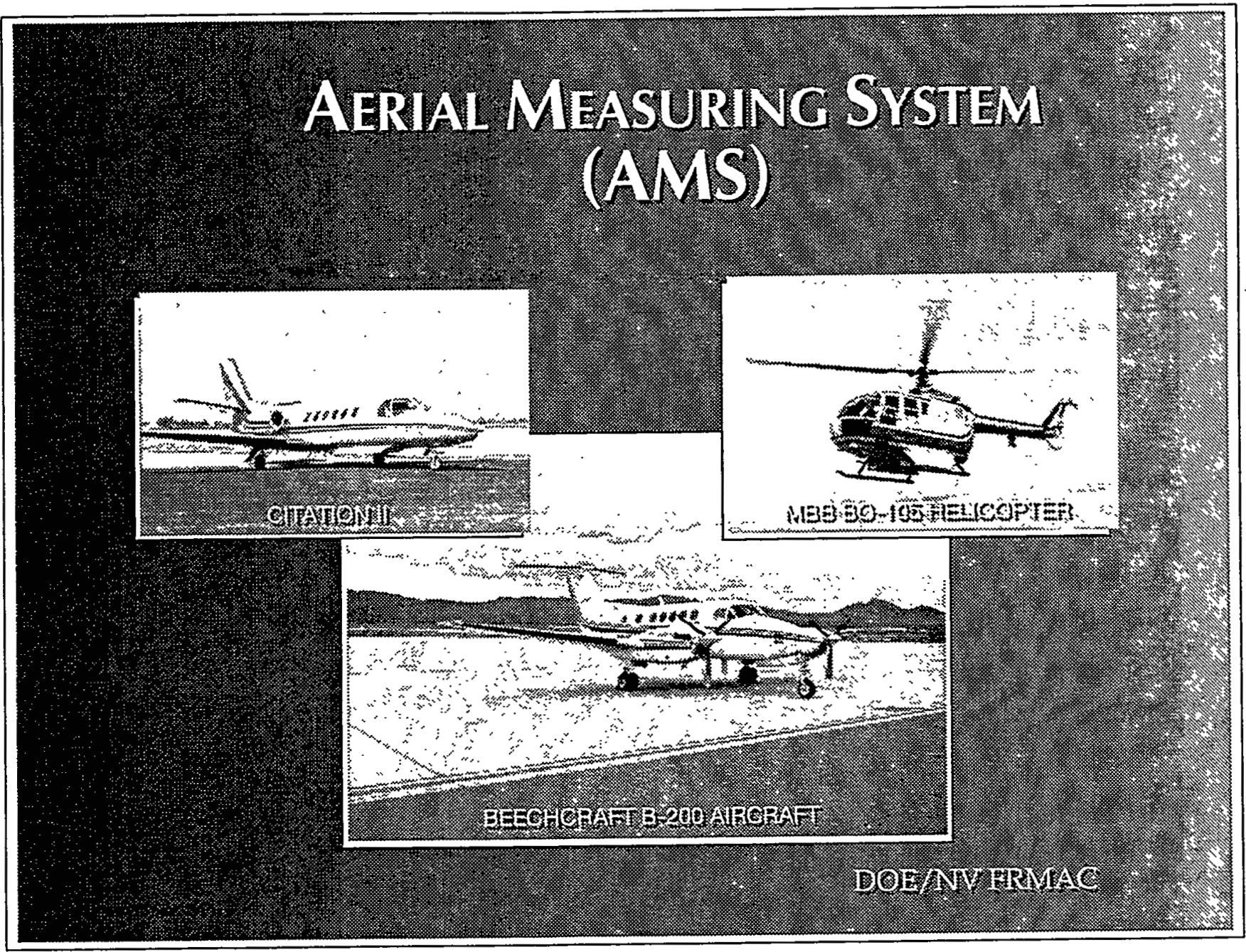

FIGURE 4. AMS PLATFORMS

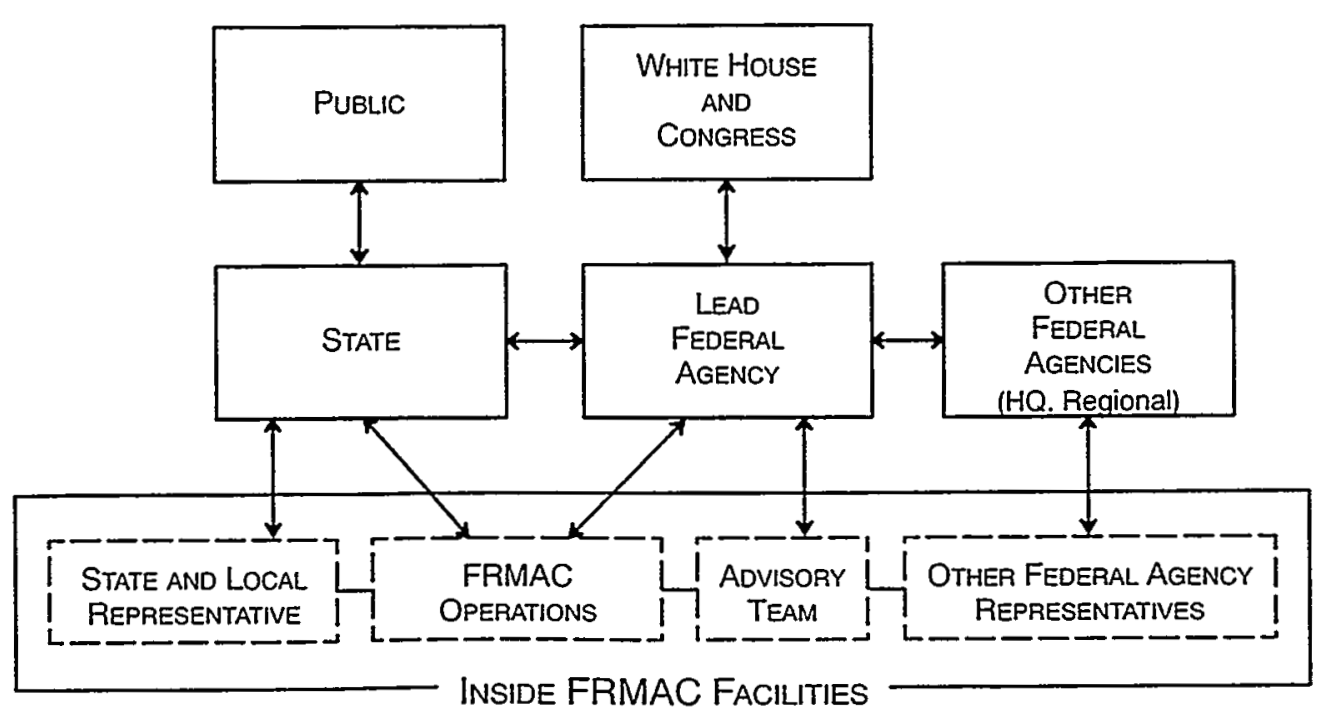

FIGURE 5. FRMAC RESPONSE OPERATIONAL STRUCTURE 


\subsection{Field Organization}

The FRMAC organizational chart (see Figure 6) shows the basic and most common operational configuration during a major radiological emergency. However, this chart may be modified during smaller, less significant radiological deployments. The FRMAC may deploy to the site of the emergency with as few as 50 or as many as 500 people. A discription of key FRMAC positions and functions are given in Appendix F.

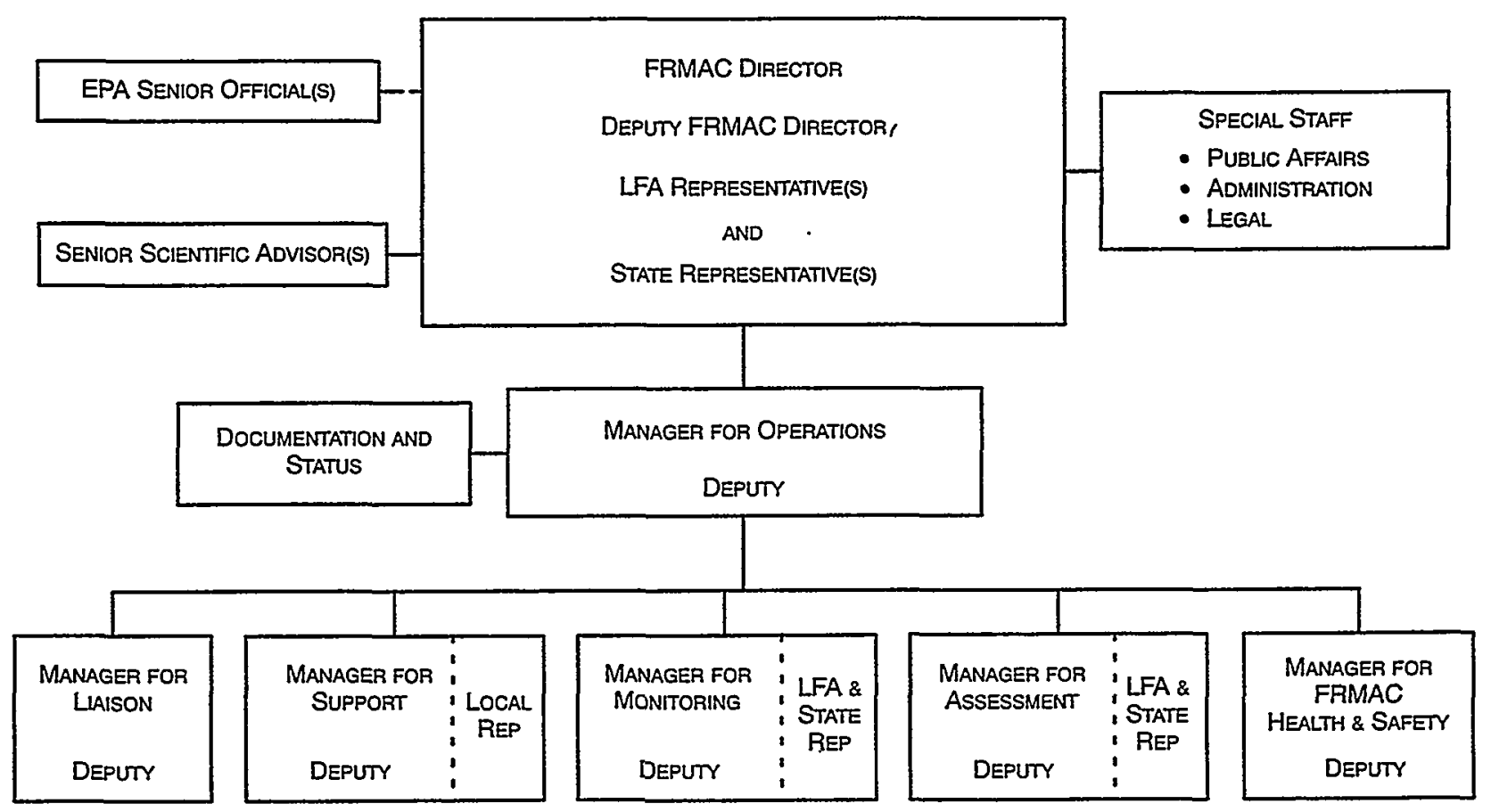

FIGURE 6. FRMAC ORGANIZATION

Figure 6 shows participation by the LFA and the state(s), which are the customers of the FRMAC. They play a major role in setting overall FRMAC priorities and activities. Their representatives are the link to the FRMAC Director and staff. They are responsible for delivering requests from their organizations to the Director and staff for FRMAC radiological products and services. Technical representatives from these organizations are located at key positions in the FRMAC to help implement their organizations' requirements and priorities.

\subsection{Information Flow and Priorities}

FRMAC's highest priority is to provide monitoring data and assessment results to the LFA, state(s), and local authorities. In the event that a release of radioactivity impacts a large area, the monitoring process will require a significant amount of time to acquire the data. Additional time will also be needed to assemble a full assessment of the extent and magnitude of that impact. The goal is to replace the early model-based data used to project initial protective actions with actual monitoring results.

Initial monitoring will focus on protecting the public and determining the magnitude, direction, and extent of released radioactivity. (See Appendix $G$ for priorities and strategies for initial monitoring, sampling, and analyzing activities.) Aerial surveys, which will later be augmented by ground monitoring, will be utilized for these purposes. These first results are then used to direct a more detailed monitoring 
effort with inhabited areas receiving first priority unless otherwise directed by the LFA and state(s). Finally, the monitoring will be continued until all of the surrounding contaminated area is characterized and impacts assessed.

Figure 7 details the internal information flow of all FRMAC environmental data. Provisions will be made in the information flow to promptly report any monitoring results that represent an immediate threat to public health. All raw data coming into the FRMAC from FRMAC teams are quickly reviewed, stamped as "raw data," and distributed to the LFA, state(s), local representatives, and all interested participants within the FRMAC facilities. Processed, evaluated, and summarized data from the Assessment Division are approved by the FRMAC Director for external distribution. These evaluated technical data are distributed formally to the LFA and state(s) simultaneously.

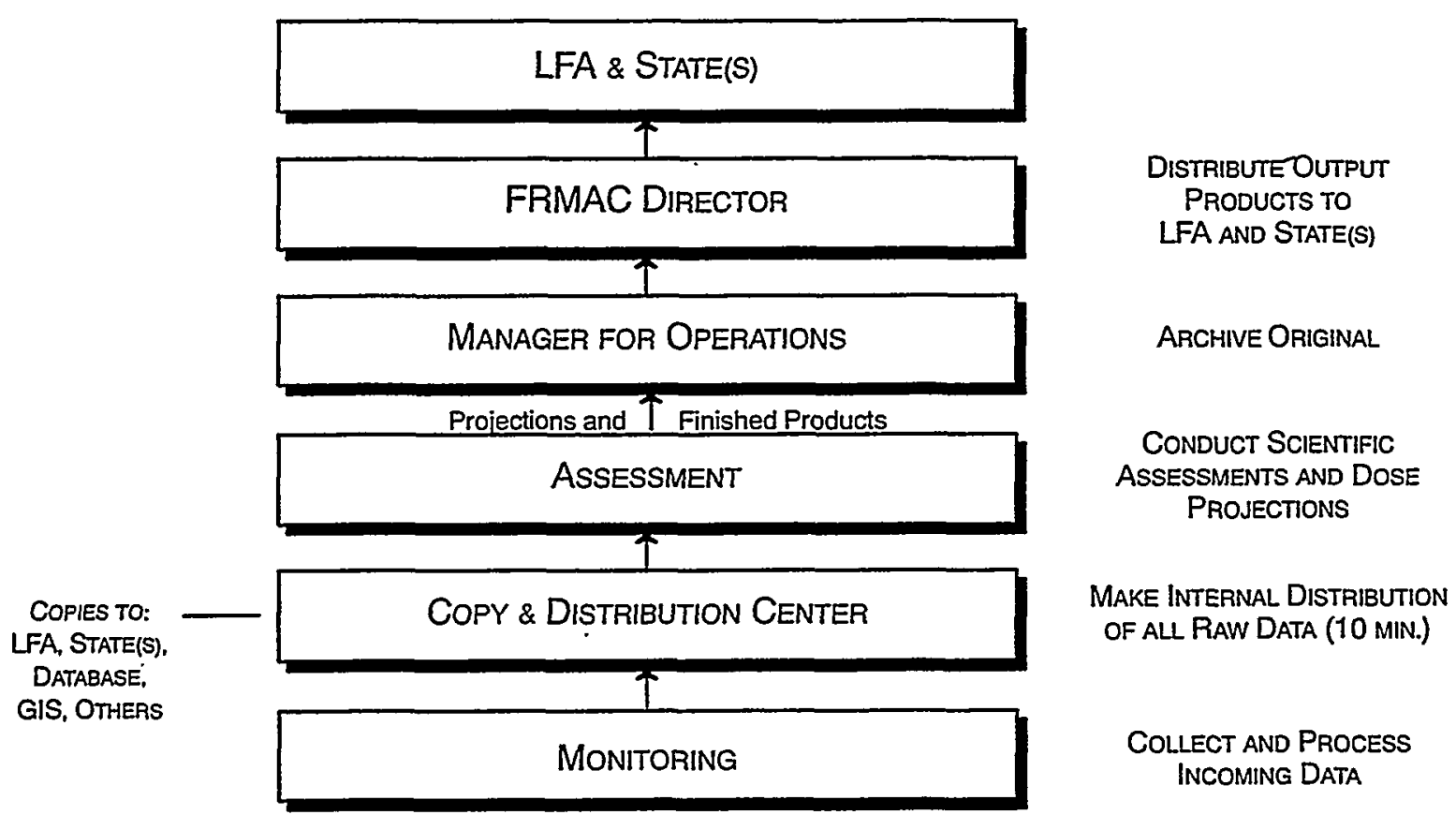

FIGURE 7. FRMAC RADIOLOGICAL DATA INFORMATION FLOW

\subsection{Interfacing}

\subsubsection{Department of Energy (DOE)}

During the emergency phase when DOE is managing the FRMAC, the FRMAC will keep DOE/NV, the affected DOE/Region, and DOE/HQ informed of the status of the emergency, the utilization of DOE assets, status of activities, and needs for additional resources, if applicable. Radiological data and results, if requested, will be transmitted to DOE/NV, DOE/Region, and/or DOE/HQ, when approved for distribution by the LFA. DOE will maintain an independent liaison for this purpose.

\subsubsection{Lead Federal Agency (LFA)}

The FRMAC Director will initiate discussions with the LFA staff as soon as technical assistance is requested. These discussions will address the conditions and status of the emergency and possible 
off-site consequences. Once the FRMAC is established, the LFA will provide appropriate status updates to the FRMAC through an LFA representative located at the FRMAC. The representative will be the primary channel for transmitting the LFA off-site monitoring and assessment requirements to the FRMAC and the distribution of the FRMAC'S assessed data to the LFA.

\subsubsection{State(s)}

To facilitate the requests from the state(s) to the FRMAC and the flow of assessed data from the FRMAC to the state(s), liaison personnel will be exchanged. Also, state and local advisors are invited to be incorporated into the FRMAC. Director's senior staff (see Figure 8) as well as the Monitoring, Assessment, and Support Divisions. Because of their local and professional knowledge, advisors provide valuable assistance in the efficient and optimal operation of the FRMAC in meeting the requirements of the state(s).

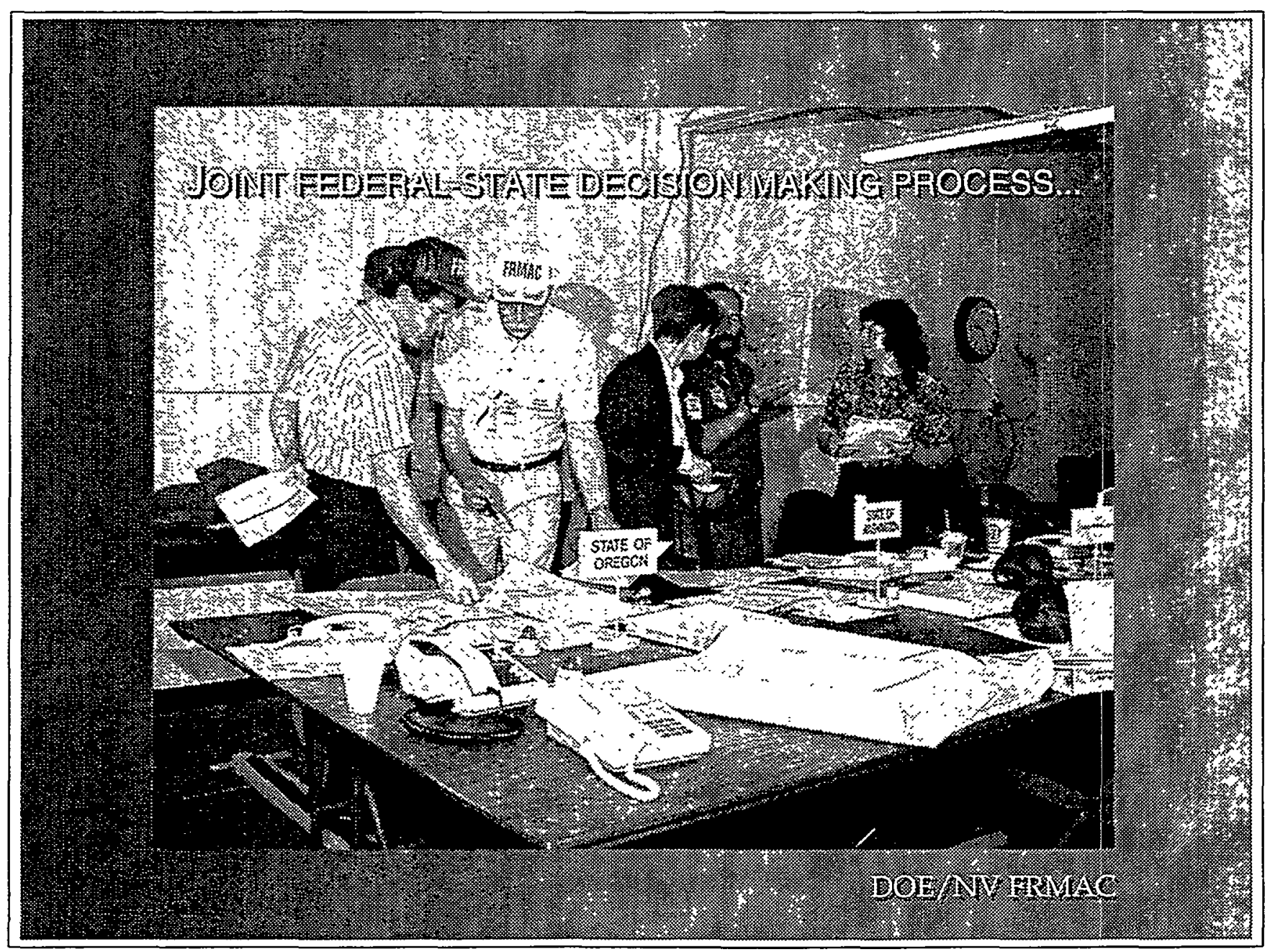

FIGURE 8. EXERCISE INTERACTIONS WITH STATE REPRESENTATIVES

\subsubsection{Environmental Protection Agency (EPA)}

The EPA will be notified if a FRMAC has been requested for a radiological emergency. The EPA provides a senior representative in the FRMAC to ensure that data collected and recorded in the data 
center provide the necessary information for long-term reentry and recovery considerations and can be used as a basis for developing a long-term monitoring plan. Once the emergency is stabilized and at an agreeable time, the EPA Senior Official will assume management of the FRMAC from DOE.

\subsubsection{Other Agencies}

As needed and as requested by the LFA, other signatory agencies to the FRERP are provided space and support to integrate their activities into the FRMAC operations. Many agencies provide key specialists in technical areas of importance to the FRMAC. Included are specialists in food crops, milk production, water supplies, and critical industries. As full participants in the FRMAC, these agencies become part of the monitoring and assessment technical teams to ensure that their areas of concern are addressed. These federal agencies may include the EPA, NRC, DOD, USDA, HHS, and NOAA and others as needed. The responsible facility operator may also be represented at the FRMAC to provide updates on facility status.

\subsubsection{Community Interaction}

Due to the close working relations between the FRMAC elements and the surrounding communities, tribal, county, and local governmental officials as well as emergency service liaison personnel will be invited to interact directly with the FRMAC as requested by the state(s). If requested, the FRMAC will provide liaison representatives to tribal, county, and local emergency operations centers. 


\section{APPENDIX A}

\section{FEDERAL AGENCY SIGNATORIES TO THE FEDERAL RADIOLOGICAL EMERGENCY RESPONSE PLAN (FRERP)}

Department of Agriculture (USDA)

Department of Commerce (DOC)

Department of Defense (DoD)

Department of Energy (DOE)

Department of Health and Human Services (HHS)

Department of Housing and Urban Development (HUD)

Department of the Interior (DOI)

Department of Justice (DOJ)

Department of State (DOS)

Department of Transportation (DOT)

Department of Veterans Affairs (VA)

Environmental Protection Agency (EPA)

Federal Emergency Management Agency (FEMA)

General Services Administration (GSA)

National Aeronautics and Space Administration (NASA)

National Communications System (NCS)

Nuclear Regulatory Commission (NRC) 


\section{APPENDIX B \\ FEDERAL RADIOLOGICAL MONITORING AND ASSESSMENT CENTER (FRMAC) DATA OUTPUT PRODUCTS}

Without a specific request for information, the Lead Federal Agency (LFA), state(s), and local authorities can expect that the FRMAC will work toward producing the generic products listed in the following sections. The majority of these products will be produced within the FRMAC by the Assessment Division. They will be presented with some perspective on the radiological situation, as known at the time, in a form readily understandable to managers and decision-makers.

\section{B.1 Plume Dispersion and Dose Projections}

The Lawrence Livermore National Laboratory's Atmospheric Release Advisory Capability (ARAC) will provide plume and dose projections when provided with the current meteorological data and estimated source term. As a signatory agency to the FRERP, Department of Commerce, National Oceanic and Atmospheric Administration personnel from the Air Resources Laboratory will additionally provide plume projections and a wide variety of meteorologic data and forecasts. ARAC predictions will supplement those made by the facility operator, LFA, state(s), and other federal agencies. Projections will be revised as verified field measurement data become available.

\section{B.2 Aerial Survey Data}

The Department of Energy's first Aerial Measuring System (AMS) mission would likely be performed in a serpentine pattern to cover the entire deposition area expeditiously (see Appendix $\mathrm{C}$ ). The results of this first mission are expected to identify the extent of the measurable contamination in both width and length, the major isotopes contributing to the aerial results, and an estimated level of contamination (exposure rates or isotope concentrations).

Later missions will involve more detailed surveys. Each helicopter mission or flight is expected to take from two to three hours, with the results available one to three hours after a mission is completed. These results will be reviewed and issued to the LFA, state(s), and local authorities as soon as possible after the completion of each survey mission. AMS flights may involve the use of both helicopter and fixed-wing aircraft utilizing large sodium iodide gamma detectors. Sensitivities are such that small changes in background can be detected (less than 1 microroentgen per hour).

\section{B.3 Reviewed Raw Data}

Ground-based radiation data (including exposure rates, sampling results, and isotopic concentrations of deposited activity) will be reviewed by the Monitoring Division, stamped "raw" data, and provided to the LFA, state(s), and local authorities within the FRMAC facilities. Specific data points (required by the LFA, state(s), or other agencies) may be needed, particularly in the initial stages of an emergency when complete data are unavailable. These reviewed raw data will be screened for complete information such as times, locations, units, exponents, and instruments used. The review will also provide some assurance of consistency within the product since it is reviewed against current knowledge of the overall radiological situation. Reviewed raw data may also include data from samples of water, 
soil, vegetation, food products, and any other sample media. Evaluation consistent with potential health hazards may be included.

\section{B.4 Summarized Data}

Environmental radiation data from field teams and laboratories will be entered into a database for both short-term and long-term storage and retrieval. As required, the data can be condensed and summarized to show the radiation situation in specific areas or to correlate sample media from different types of surveys. For example, a summarized data sheet could be generated to show all of the external exposure rate or specific nuclide data taken in certain sectors, districts, or population areas over a given time period.

\section{B.5 Exposure Rate and/or Contamination Contours}

FRMAC provides radiation contours in a color-coded format showing where the contamination is located and the associated radiation levels. Initially, projections of radiation patterns from radiological dispersion models are likely to be the only ones available. As environmental surveys are conducted, these contours will be refined or changed to be consistent with data from actual measurements. It is anticipated that contamination contours will be updated every few hours to represent the latest information received in the FRMAC. The contour levels may be in exposure rates or isotopic concentrations, depending on the type of emergency and preferences of the LFA, state(s), and local authorities.

\section{B.6 Dose Projections from Actual Measurements}

Once enough data points are available, more realistic projections of doses to individuals and/or groups of individuals can be produced. The contour levels will include those applicable to the Protective Action Guides (PAGs) as well as any other levels of interest. For example, it may be appropriate to produce contours of the projected four-day, one-month, first-year, second-year, and fifty-year whole-body dose equivalent from external radiation for outdoor locations and/or for sheltered locations. A variety of assumptions of modifying factors may be included in these dose projections including, but not limited to, weathering, resuspension, structure shielding, and occupancy rates. The FRMAC dose projections will be as realistic as possible using reasonable assumptions and transfer values consistent with the uncertainties involved. Such assumptions will be documented or their sources referenced and included with the assessments.

\section{B.7 FRMAC Data Center}

All of the environmental radiological data acquired by or furnished to the FRMAC will be stored in the FRMAC Data Center. It will be comprehensive because it is intended to include every off-site environmental radiological data point. Every data point acquired by FRMAC will be traceable to an individual instrument, survey team, calibration, and procedure.

The long-term design objectives of the Data Center are to (1) build a comprehensive and traceable compilation of all environmental radiological data for long-term retention and use by the Environmental Protection Agency, the LFA, state(s), and local authorities and (2) archive all information to reconstruct knowledge of the radiological situation some time in the future. 


\section{B.8 Geographic Information System (GIS) Products}

The GIS is a computerized database management system which provides for the capture, storage, retrieval, analysis, and display of spatial (locationally defined) data. By having layers of information displayed on a computer screen and/or map, a person can see the relationship of one piece of information to another. The GIS is also a database in that attributes of a given piece of data can easily be referenced. For example, a specific school can be located on a map and applicable information about that school can be extracted by the database. The GIS can also calculate areas of interest. For example, a land-use data layer can be overlaid onto a radiation plot to calculate the area of a given type of land use that lies within a certain radiation zone.

Layers of information within the GIS may include (1) geographic base data, (2) administrative data, (3) emergency response data, (4) land cover/land use, (5) critical industries, (6) radiation data, (7) dispersion model output, and (8) image data.

These GIS layers may include locations of evacuation routes, police and fire stations, hospitals and clinics, operations centers, shelters, and institutions (schools, prisons, and nursing homes). Radiation data could include baseline background levels, environmental thermoluminescent dosimeter locations, continuous location of survey teams, AMS data, location of measurements and samples by type, exposure rate contours, integrated one-year dose projection contours, and isotopic concentration contours by dominant isotope.

\section{B.9 Tailored Format for Users}

The FRMAC will present the off-site environmental radiological data to the LFA, state(s), and local authorities in a recognizable and useable format and in a perspective understandable by managers and decision-makers. Insofar as possible, there will be presentation-quality graphics (both hard copies and transparencies) that summarize data and impacts. Discrete data will be prepared in a clear, concise form, organized specifically for a particular purpose. Radiation levels in commonly used units and/or in values relative to recognizable PAG levels will be used. Where possible, plotted or contoured radiation levels will be in standard FRMAC color schemes. Information transmitted by fax, Geographic Information System (GIS), or still video will be produced in an easily readable and concise format with sufficient information to properly present the required data. Whenever possible, the provided information will be tailored to meet the intended users' purposes. 


\section{APPENDIX C}

\section{AERIAL MEASURING SYSTEM (AMS)}

\section{C.1 Introduction}

The AMS is a key element of the Department of Energy (DOE) response to a large radiological incident. Large areas can be surveyed quickly to assist the Lead Federal Agency (LFA) and the states in determining the impact of the emergency. The AMS assets, which are operated and maintained by the DOE Nevada Operations Office (DOE/NV), Remote Sensing Laboratory, are located at Nellis Air Force Base (AFB) in Las Vegas, Nevada, and at Andrews AFB near Washington, D.C.

\section{C.2 Activation}

Before the deployment of the AMS assets, authorization for their release must be approved by DOE Headquarters (DOE/HQ). This authorization is initiated by a request for assistance from the LFA, state(s), or other DOE emergency response groups to the DOE/HQ Emergency Operations Center. Until the FRMAC Advance Party arrives on scene, the Radiological Assistance Program (RAP) Team Leader at the scene will contact and coordinate the AMS flights with the LFA, state, and local representatives at the scene. Dependent upon flight transit times, location, and aircraft deployed, the AMS missions could begin 4 to 16 hours after the DOE/NV has received the authorization to deploy.

\section{C.3 Capabilities}

AMS-equipped, fixed-wing aircraft are instrument rated, capable of all weather operation, and equipped for penetration of a contaminated air mass, if required. Fixed-wing aircraft operate at altitudes as low as 152 meters (500 feet) above ground level and as high as the aircraft's operational ceiling, which is approximately 16,700 meters (35,000 feet) Mean Sea Level. Dependent upon flight conditions, the fixed-wing aircraft's optimum flying time is five hours. Standard instrumentation includes two 4- $\times$ 4- $\times 16$-inch sodium iodide gamma scintillation detectors, whole gas sampling equipment, one high-volume charcoal and one paper-filter sampler, survey meters, recording equipment, radar altitude and Global Positioning System (GPS) position tracking equipment, direct readout hardware, and data analysis equipment. The data are partially analyzed on-board and are stored on magnetic tape cartridges for detailed analysis upon landing. The paper air filter can be removed and analyzed on-board.

AMS-equipped helicopters operate only under Federal Aviation Administration visual flight rules and will not be deployed during poor weather conditions. Helicopters operate at altitudes as low as 30 meters (100 feet) above ground level, but their actual operational altitudes will be dictated by flight safety concerns. Dependent upon flight conditions, the helicopter's optimum flying time is two to three hours. Standard instrumentation includes eight $2-\times 4-\times 16$-inch sodium iodide thallium activated $(\mathrm{Nal}(\mathrm{T} l))$ detectors, two shielded, upward-looking detectors, data formatting and recording equipment, radar altitude and GPS position tracking equipment, direct readout hardware, and data analysis equipment. The data are partially analyzed on-board and are stored on magnetic tape cartridges for detailed analysis upon landing.

Dependent upon the mission objectives, a precision optical camera, a thermal infrared scanner, and other radiation detectors could also be mounted on the aircraft. 


\section{C.4 Missions}

The AMS aircraft can be used to track the radioactive cloud and/or to confirm the release of radioactive materials into the air. The mission will provide information regarding the location, size, intensity, dominant isotopes, source term and migration pattern of the radioactive air mass or cloud. If cloud sampling is required, it will occur at the end of the mission because of contamination of the aircraft. All tracking flights will normally be conducted by the fixed-wing aircraft unless special conditions require the use of the helicopter.

An initial AMS flight can be made to rapidly, but coarsely, map in one flight the residual fallout pattern and intensity of contaminated debris or material that may have been deposited after passage of the radioactive air mass or cloud. The AMS-equipped aircraft will fly a serpentine pattern of uniformly spaced parallel flight lines that will encompass a 10-mile circle about the incident site and the entire area suspected of being contaminated. During the flight, cursory radiological data such as peak exposure rates, the spectral summation count rate relative to background, and the dominant isotopes will be radioed to the AMS ground control. The initial mapping flight will normally be conducted and limited to daylight hours. However, nighttime flights will be considered on a case-by-case basis. Upon landing, more detailed data analysis will be performed in the computer analysis laboratory mobile van. The data processing time required to complete the detailed analysis is approximately one to three hours. Mission deliverables are:

- Inferred exposure rate along deposition center line

- Identification and magnitude of dominant isotopes (gamma energy spectra)

- Letter plot map of inferred exposure rate (exposure rate footprint)

After the initial broad survey, detailed radiological surveys will be performed to measure and map the extent of the residual fallout deposition, determine the averaged surface area exposure rate, and identify the specific radionuclides responsible for the contamination and their relative intensities.

Normally, to perform an aerial radiological survey of an area, the AMS-equipped aircraft must fly a series of parallel flight lines at as low an altitude and ground speed as can be safely achieved (see Figure C-1).

For the helicopter system, the nominal survey altitude is 46 meters (150 feet) above ground level with a flight line spacing of 76 meters (250 feet) at a ground speed of 36 meters per second ( 70 knots). For the fixed-wing system, the nominal survey altitude is 152 meters (500 feet) above ground level with a flight line spacing of 305 meters ( 1,000 feet) at a ground speed of 76 meters per second ( $150 \mathrm{knots}$ ).

The preferred aerial platform for performing a detailed aerial survey is the helicopter because of its larger-volume Nal(Tl) detector array, lower flying altitude, and greater spatial resolution. Flying at an altitude of 46 meters ( 150 feet) will provide a ground monitoring window (field of view) of approximately 92 meters (300 feet) in width. In this manner, the helicopter can map the ground deposition at a rate of about 10 square kilometers per hour (4 square miles per hour). The radiological survey flights are normally limited to daylight hours. However, nighttime flights will be considered on a case-by-case basis.

After each survey flight, detailed data analysis is performed in the computer analysis laboratory mobile van. The data processing time required to complete each set of flight data is approximately one to three hours. Completed survey deliverables are:

- Contour map of inferred exposure rate at one meter above ground level

- Contour map(s) of specific isotope surface area activity

- Identification and magnitude of dominant isotopes (gamma energy spectra)

Other missions include aerial photography, thermal infrared scanning, and wind sounding. 


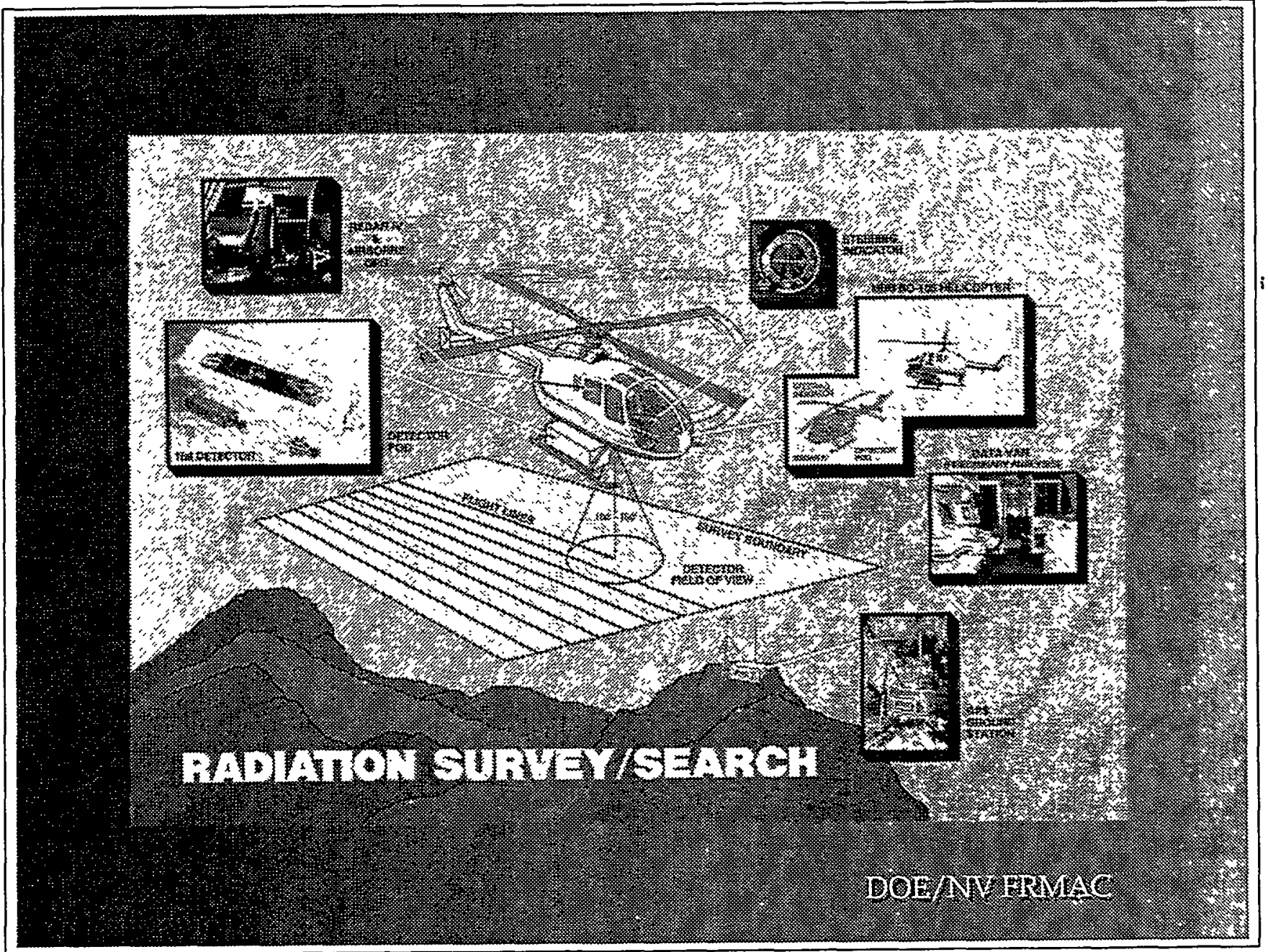

FIGURE C-1. TYPICAL AERIAL RADIOLOGICAL SURVEY SETUP

\section{C.5 Aerial Radiological Survey Sensitivities}

The minimum detectable activity limits of the AMS aerial platforms for a typical radiological survey are shown in Table C-1. Sensitivity values are given for typical isotopes in units of microcuries per square meter $\left(\mu \mathrm{Ci} / \mathrm{m}^{2}\right)$, assumed to be surface deposition with no mixture in the soil. The minimum detection level of the inferred exposure rate for both aerial platforms is less that one microroentgen per hour above background. Detection sensitivities will vary, depending upon altitudes flown, line spacing, deposition variability, and analysis processing.

\section{C.6 Response Times}

Two BO-105 ${ }^{1}$ helicopters are stationed at Andrews AFB near Washington, D.C. and two are stationed at Nellis AFB in Las Vegas, Nevada. One B- $200^{2}$ fixed-wing aircraft is stationed at each location. Flight times from both locations for both types of aircraft are shown in Figure $\mathrm{C}-2$.

\footnotetext{
1 BO-105 refers to a Messerschmitt-Bolkow-Blohm twin jet engine helicopter used by the AMS for low-altitude radiation survey detection and monitoring.

2 B-200 refers to a Beechcraft King Air twin turboprop engine, fixed-wing aircraft used by the AMS for radioactive plume tracking, air sampling, and wind sounding measurements.
} 


\begin{tabular}{|c|c|c|c|}
\hline \multirow[b]{2}{*}{ Radionuclide } & \multirow{2}{*}{$\begin{array}{l}\text { Photopeak } \\
\text { Energy } \\
\text { (kiloelectron } \\
\text { Volts(keV)) }\end{array}$} & \multicolumn{2}{|c|}{ Surface Area Deposition ${ }^{a}\left(\mu \mathrm{Ci} / \mathrm{m}^{2}\right)$} \\
\hline & & $\begin{array}{l}\text { Fixed-Wing } \\
\text { Aircraft }^{\mathrm{b}}\end{array}$ & Helicopterc \\
\hline Americium-241 ( $\left.{ }^{241} \mathrm{Am}\right)$ & $60 \mathrm{keV}$ & 7.3 & 0.20 \\
\hline Cesium-137 ( $\left.{ }^{137} \mathrm{Cs}\right)$ & $662 \mathrm{keV}$ & 0.30 & 0.06 \\
\hline Cobalt-60 $\left({ }^{60} \mathrm{Co}\right)$ & $1,173-1,333 \mathrm{keV}$ & 0.05 & 0.02 \\
\hline lodine-131 $\left({ }^{131} l\right)$ & $365 \mathrm{keV}$ & 0.50 & 0.07 \\
\hline Plutonium-239 (239Pu) & $375 \mathrm{keV}$ & 25,600 . & 3,600 . \\
\hline
\end{tabular}

aMinimum detectable activity value is the three-sigma value due to the counting statistics in the spectral energy window of the photopeak of interest.

bFixed-wing systems are equipped with two 4- $\times 4-\times 16$-inch Nal(Tl) logs flown at an altitude of 152 meters (500 feet) above ground level, a flight line spacing of 305 meters (1,000 feet), and an average ground speed of 76 meters per second (150 knots). Flying at higher altitudes (c.g., 1,500 ft) will reduce detectibility by a factor of 3 or more.

CHelicopter systems are equipped with eight 2- $\times 4-\times 16$-inch $\mathrm{Nal}(\mathrm{Tl})$ logs flown at an altitude of 46 meters (150 feet) above ground level, a flight line spacing of 76 meters (250 feet), and an average ground speed of 36 meters per second (70 knots). Processing the data using a 9-second averaging routine may enhance the detectability by a factor of 3 or more.

For fixed-wing flight times the concentric circles depict 240 miles, representing one hour of aircraft flight time, taking into account maximum mission weights and adverse winds. Refueling stops of a onehour duration will generally occur at four-hour intervals. For helicopter flight times, the concentric circles show 160 miles, representing two hours of flight time, taking into account maximum mission weights and adverse winds. Refueling stops of up to one-hour duration will generally occur at threehour intervals. Maximum daily flight time will not exceed eight hours for a single pilot crew or ten hours for a two pilot crew. Specific flight routes and times for both types of aircraft will be determined by the pilot-in-command after analysis of weather, aircraft loading, and other pertinent mission information. 
Fixed-Wing (Each Circle $=1$ Hour Flight Time, 240 miles)

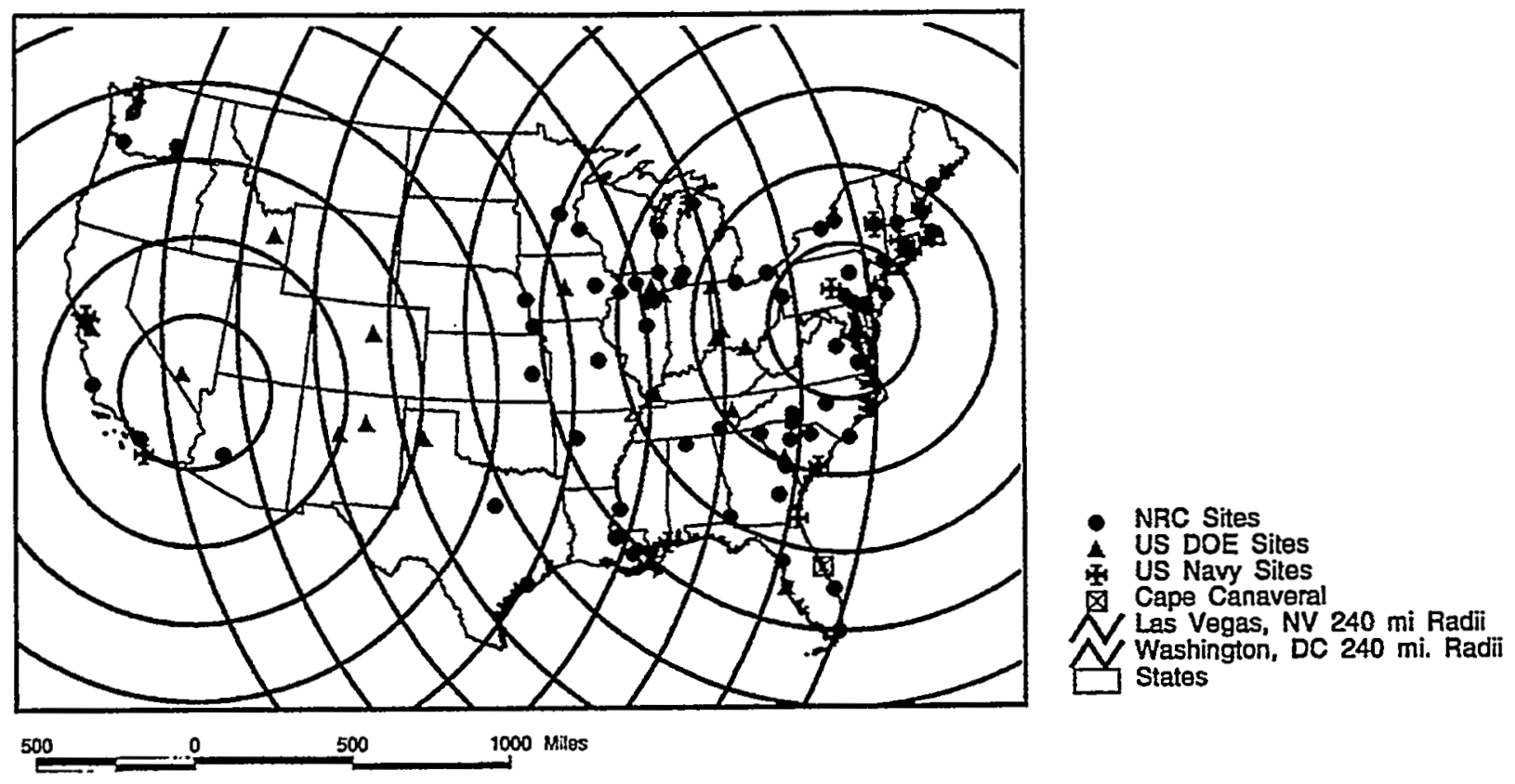

Helicopter (Each Circle $=2$ Hour Flight Time, 160 miles)

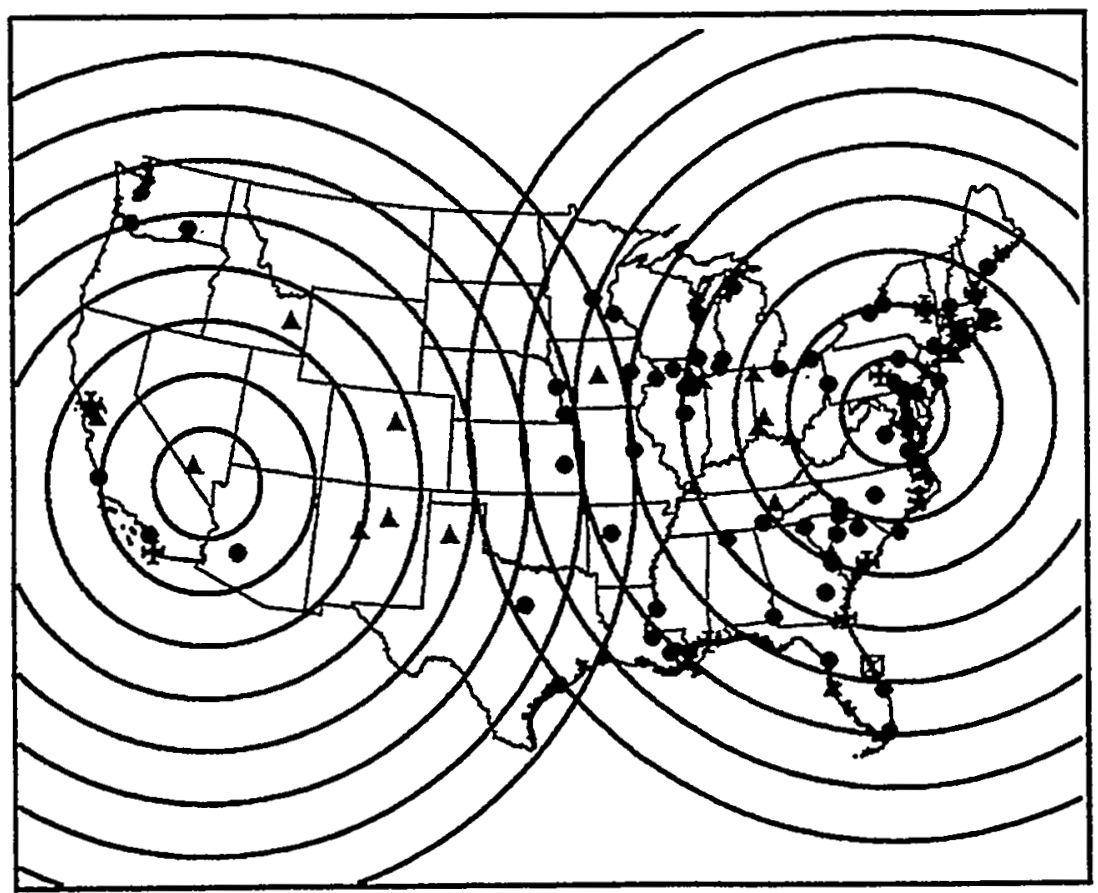

- NRC Sites

US Navy Sites

NASA Sites

Las Vegas, NV160 mi Radii Washington, DC 160 mi. Radii States

500

500 1500 Miles

FIGURE C-2. FLIGHT TIMES 


\section{APPENDIX D \\ FEDERAL RADIOLOGICAL MONITORING AND ASSESSMENT CENTER (FRMAC) SITE SELECTION CONSIDERATIONS}

\section{D.1 Overview}

FRMAC has the capability and available assets to be self-sufficient when activated. These resources help to ensure that FRMAC minimally impacts state and local economies without being a burden to them. The selection of a FRMAC site will include consideration of housing, airport facilities, and vehicle availability. All of these factors may be affected by the magnitude of the emergency, evacuation status, presence of an airborne radioactive plume, and other factors that will only be known at the time of the emergency. In addition, interaction with state and local monitoring activities and the location of emergency operations facilities will be considered. Conditions at the time will dictate FRMAC site selection.

\section{D.2 Site Specifications}

Whenever possible, a FRMAC will be located within 10 to 15 miles of the emergency scene to effectively carry out its mission. Because of the expected use of the Department of Energy's (DOE) Aerial Measuring System assets, the FRMAC location should be convenient to an airport or a helicopter pad to facilitate rapid turnaround.

A FRMAC site for a large-scale deployment requires an indoor workspace of from 10,000 to 20,000 square feet. Space must be available for administrative functions and for specialized equipment, such as Geographic Information System, communications, photography, and still video. A large, fenced staging area is needed for shipping and storage of supplies, large trucks and analysis vans, and the setup of outdoor communications equipment. Adequate electrical service must be available. However, DOE has the capability of providing for sufficient electrical service, if required.

The availability and suitability of the following facilities and resources will be considered in the selection of a FRMAC site:

1. Site access-airport and/or major highways to accommodate large trucks and vans

2. Communications-clear of interference, appropriate terrain for a satellite antenna; telephone trunk lines

3. Housing - hotels or military quarters

4. Vehicle rental, including several types of large trucks

5. Medical facilities-hospital or dispensary

6. Food services-round-the-clock catered service

7. Materials and services-office supplies, minor repairs, and security

\section{D.3 Site Selection}

A FRMAC operating site will not be finally selected until an emergency occurs. This is due to the fact that the FRMAC may be responding in the aftermath of an earthquake, hurricane, or flood. A significant 
radiation release may preclude access to preselected FRMAC sites due to possible contamination. Therefore, any preselection of FRMAC sites is limited to simply identifying one or two potential locations for each major, fixed nuclear facility. The DOE Regional Coordinating Offices should be informed of the identity and location of these potential FRMAC sites.

Members of the FRMAC Advance Party, in consultation with the Lead Federal Agency, state(s) and local authorities, will make the final selection of a FRMAC site based on the current emergency conditions. Potential FRMAC locations include armories, schools, hotels, and hangars. 


\section{APPENDIXE \\ FEDERAL RADIOLOGICAL MONITORING AND ASSESSMENT CENTER (FRMAC) ADVANCE PARTY ISSUES}

\section{E.1 Introduction}

FRMAC plans include the deployment of an Advance Party to the emergency site as soon as possible after notification to deploy. The primary purpose is to prepare for the arrival of the FRMAC Main Party in order to ensure an effective and timely FRMAC operation in support of the LFA and the state(s). This Appendix contains FRMAC Advance Party issues, including a meeting agenda. These issues should to be used as a guide for planning purposes. Actual FRMAC Advance Party actions and meeting agendas may be modified to meet the emergency conditions.

\section{E.2 Prior to Departure for the Emergency Site}

- Identify DOE official who will meet the Advance Party.

- If not upon arrival at the airport, when and where?

- Identify the LFA official who will meet the Advance Party.

- If not upon arrival at the airport, when and where?

- Notify the LFA, state, local, and/or facility representatives of the tentative arrival schedule of the Advance Party and establish a tentative date, time, and location for the Advance Party Meeting.

- FAX to LFA, state, local, and/or facility representatives the Advance Party Meeting Agenda.

- Obtain ARAC plot.

\section{E.3 Upon Arrival On-Scene}

- Notify DOE/NV, DOE/HQ, LFA, and state of your arrival and get updates.

- Obtain specifics for the Advance Party Meeting.

- Meet with an on-scene DOE official, RAP Team Leader, and AMS Team Leader

- Identify status, activities, and problem areas.

- Is DOE/HQ and DOE/NV being kept up-to-date?

- What DOE/other federal assets have been activated, are enroute, or on-site?

- Suggestions for locating the FRMAC.

- Obtain updated ARAC plot.

- Meet with LFA official to identify status, activities, and problem areas.

\section{E.4 Advance Party Meeting Agenda}

- Introductions 
- Status of emergency by LFA and/or utility.

- Status of release:

Has the release terminated?

How many releases have occurred?

Estimate of source term.

Dominant isotopes.

Wind direction during releases.

On-site and off-site monitoring results.

- Is the situation stable?

- Atmospheric prediction plots.

- Significant actions in the past 12 hours.

- Major activities planned for the next 12 hours.

- Status of emergency from state and/or local perspective:

- What protective actions have been implemented and/or are pending?

- Who has the responsibility for initiating public protective actions; i.e., state, tribal, county, local authorities?

- Are the protective action guides in use the same as EPA/USDA/FDA's?

- Problem areas.

- Are there any significant confounding conditions which could impact FRMAC operations; e.g. , hazardous materials associated with the emergency, flood damage, earthquake damage, major road work, etc.?

- Significant actions in the past 12 hours.

- Major activities planned for the next 12 hours.

- Identify LFA, state, and local concerns and highest FRMAC priorities.

- Establish communication channels.

- Identify primary LFA and state/local contacts and Rad decision makers.

- Identify LFA and state/local individuals to work with FRMAC Director.

- FRMAC Director's briefing.

- Identify the DOE Energy Senior Official.

- Explain DOE command structure.

- Provide overview of FRMAC operations:

Function.

Resources and operations.

Time line for arriving resources and an operational FRMAC.

Decision making and priorities.

Data flow.

Expected products.

- Placement of LFA, state, local, and FRMAC liaisons.

- Will the state/local monitoring effort fold into the FRMAC?

- Concerns and suggestions from the LFA, state, and/or local regarding FRMAC location.

- Can the state/local representatives identify an individual to assist FRMAC to secure site and become operational? 
- Define initial Aerial Measuring System radiological survey mission.

- Identify state/local individual to assist flight operations. (Issues: Where will the aircraft land? Is fuel available? What frequencies will be used? FAA clearances? etc.)

- Identify LFA and state/local individuals to work with FRMAC in developing the initial FRMAC Monitoring and Sampling Plan.

- Identify LFA and state/local individuals to work with FRMAC Dose Assessment.

- FRMAC activities planned for the next 12 hours.

- Future meetings?

- Other issues. 


\section{APPENDIX F}

\section{FEDERAL RADIOLOGICAL MONITORING AND ASSESSMENT CENTER (FRMAC) POSITION DESCRIPTIONS}

Key FRMAC personnel are described in the following functional profiles.

\section{F.1 FRMAC Director}

The FRMAC Director, appointed by the manager of DOE's Nevada Operations Office (DOE/NV), with DOE Headquarters (DOE/HQ) concurrence, is the Energy Senior Official $(E S O)^{1}$ managing DOE offsite resources. The FRMAC Director oversees the activities of all FRMAC personnel provided by any DOE Operations Office, DOE laboratory, DOE contractor, and other federal or state agencies. The Director is responsible for the overall execution of the FRMAC response. The Director is also responsible for establishing communication with the Lead Federal Agency (LFA), the state(s), local authorities, and other federal agencies to carry out the objectives and operations of the FRMAC.

\section{F.2 Deputy FRMAC Director}

The Deputy FRMAC Director serves as the Director during the evening shift of an operational FRMAC. The duties of the Deputy are the same as those of the FRMAC Director.

\section{F.3 LFA and State Representatives}

The LFA and state representatives work directly with the FRMAC Director and Deputy in establishing FRMAC priorities and in reviewing overall FRMAC activities. The LFA representative coordinates requests from the participating federal agencies and, with state representatives, provides input to the FRMAC Director about overall needs for off-site monitoring and assessment to fulfill the priorities of the LFA and state(s).

\section{F.4 Environmental Protection Agency (EPA) Senior Official}

The EPA becomes responsible for FRMAC management after the emergency phase is over. Until this transfer, the senior EPA official functions as a senior staff liaison official and interfaces directly with the FRMAC Director.

\section{F.5 Senior Scientific Advisor (SSA)}

The SSA is a national expert in radiation health effects and environmental impacts of the radioactive material involved. The SSA (with staff if needed) will provide an overview to the FRMAC Director about the health effects and environmental impacts of the emergency. The SSA will advise the FRMAC Director about technical activities to meet the overall FRMAC objectives and will work closely with the technical managers in the field organization, as well as LFA, state, and local officials, if necessary.

\footnotetext{
1 During a nuclear weapons accident, a nuclear terrorist threat, or when DOE is the LFA, DOE will appoint both an ESO and a FRMAC Director.
} 


\section{F.6 Special Staff}

The Special Staff assists and advises the FRMAC Director concerning administrative, legal, and public affairs. The Legal Coordinator will provide legal advice to the FRMAC Director concerning FRMAC operations and personnel. The Public Affairs Officer (PAO) will advise the FRMAC Director about news media activities associated with the emergency and will interface with the LFA and state PAOs and media personnel, where appropriate.

\section{F.7 Manager for Operations}

The Manager for Operations assists and advises the Director in field implementation, execution, and coordination of all resources at the FRMAC. The Manager for Operations advises the Director about all staff and emergency functions and monitors the status of all requests and events flowing through the FRMAC. The manager will be the focal point for authorization for all persons coming into the FRMAC, both participants and visitors.

The Manager is responsible for information flow and documentation within the FRMAC and for ensuring the completion of each request made by the LFA and state(s). The Manager will serve as a conduit for information provided to the FRMAC Director by the Division Managers (Support, Assessment, Monitoring, Liaison, and the FRMAC Health and Safety) and review all data prior to presenting them to the Director.

\section{F.8 Manager for Liaison}

The Manager for Liaison provides information through FRMAC technical liaison representatives to the LFA, state(s), local authorities, FEMA Disaster Field Office (DFO), and other agencies and/or emergency response centers, as needed. The liaisons may also be a conduit for requests to the FRMAC.

The liaison function ensures timely transmittal of critical monitoring and assessment information to the LFA, state(s), the facility operator (if there is one), and other federal agencies, as approved by the LFA. The resolution of conflicts in data from other sources is facilitated and expedited through the FRMAC liaison personnel who are assigned to the response facilities. Liaisons, located in other response centers (not the FRMAC), communicate with the FRMAC by telephone, fax, modem, and still video.

\section{F.9 Manager for Support}

The Manager for Support is responsible for providing administrative services, communications, mechanical systems, photo and video, logistics, security, and general supplies and services (base support) to all FRMAC participants.

\section{F.10 Manager for Monitoring}

The Manager for Monitoring will coordinate and direct data acquisition personnel, including those responsible for aerial radiological surveying, field monitoring, sampling, sample analysis, and environmental dosimetry. All environmental monitoring teams working out of the FRMAC (including DOE, EPA, other federal agencies, and the state[s]) will be coordinated by the Manager. In conjunction with the SSA and the Manager for Assessment, the Manager for Monitoring evaluates the need for field information and radioanalytical data and establishes priorities for the monitoring resources. The Quality Assurance Group within the Division ensures that all monitoring measurements, sample collection, 
and derived analytical data are scientifically defensible, of acceptable known quality, and meet FRMAC requirements.

\section{F.11 Manager for Assessment}

All environmental radiation data that are gathered or received by the FRMAC flow through the Assessment Division to the FRMAC Director. The Manager oversees the handling, processing, evaluation, assessment, reporting, and archiving of all the data; reviews and assembles all of the environmental data to develop an overview status and to provide technical interpretation of the radiological situation; and ensures that the appropriate documents exist to ensure the technical integrity of the data.

The Manager for Assessment works closely with the SSA to identify monitoring and radioanalytical data needed to meet FRMAC assessment requirements. Both work closely with the Manager for Monitoring in establishing priorities for the monitoring and laboratory resources which most efficiently meet these data requirements.

\section{F.12 Manager for FRMAC Health and Safety}

The Manager for FRMAC Health and Safety is responsible for all health and safety issues for FRMAC personnel. This includes radiation protection, industrial hygiene, general safety, and medical care or treatment at the FRMAC for all federal agency and contractor FRMAC participants. The Manager will coordinate and direct all health and safety efforts in conjunction with the other FRMAC managers and will ensure that personnel radiation exposures are maintained at levels as low as reasonably achievable within the appropriate exposure standards. The Safety Coordinator (within this Division) will work with the FRMAC managers to ensure that all FRMAC operations (both inside the FRMAC facility and outside in field operations) are being conducted in a safe manner and in compliance with all DOE Orders or other applicable federal regulations. Within the Health and Safety Division are the Radiation Emergency Assistance Center/Training Site personnel and/or the regional medical coordinator who will provide appropriate information in the event that radiological medical support is requested by a federal agency or the state(s).

\section{F.13 Other Key Personnel in the FRMAC Facilities}

Other key personnel expected to be located in the FRMAC facilities, but not a part of the FRMAC operations, are described below:

\section{F.13.1 Representatives from other Agencies to the FRMAC}

Federal agencies that need information to fulfill their statutory and/or regulatory obligations are represented at the FRMAC but are not part of the FRMAC operations. These agency representatives act as information channels to and from their headquarters. They cannot, however, send radiological data to their headquarters without LFA approval. Other local agencies within the state(s), including utilities, may also be represented.

\section{F.13.2 Advisory Team}

The Advisory Team for Environment, Food, and Health, composed of representatives from EPA, USDA and HHS, provides direct support to the LFA in evaluating and recommending protective actions. 


\section{APPENDIX G}

\section{FEDERAL RADIOLOGICAL MONITORING AND ASSESSMENT CENTER (FRMAC) MONITORING, SAMPLING, AND ANALYSIS INITIAL PRIORITIES AND STRATEGIES}

\section{G.1 Advance Party Meeting}

During the Advance Party meeting with the involved state(s) and the LFA, an initial FRMAC Monitoring and Sampling Plan must be developed. To create this plan and for the FRMAC Monitoring Division (MD) to become operational, the MD representative must:

1. Identify LFA and state advisors to the MD.

2. Identify counterparts and liaisons.

3. Identify the protective actions that have been taken or are taking place in the off-site area (the $M D$ requires a hard copy, including an illustrative map, especially for the evacuated and sheltered areas).

4. Identify the monitoring and sampling activities that will be completed by the time FRMAC is operational (off-site and on-site).

a. What analyses are the samples undergoing?

b. What is the expected time when results will be available?

c. Can FRMAC obtain copies of the monitoring and analytical data? When and how?

5. Identify and obtain adequate maps (both for field teams and the MD status coordinator).

6. Identify the location of preestablished state, local, and facility off-site monitoring sites.

7. Identify local populated areas and critical facilities such as hospitals, nursing homes, and prisons.

8. Identify locations of surface drinking water supplies and open-air water treatment facilities.

9. Determine if state, local, and/or facility monitoring personnel will join the FRMAC.

a. If not, determine who is the state contact for coordinating off-site monitoring and analytical activity.

b. If state, local, and/or facility monitoring personnel join the FRMAC, determine allowable exposure levels and dose commitments. These values, which may be much different from FRMAC values, must be respected. This is also applicable to local individuals provided for driving monitoring vehicles.

10. Identify institutions, facilities, and residences located in the evacuated areas which were not evacuated or where people must reenter in the near future.

11. Determine how and when federal responders, who will be monitoring prior to an operational FRMAC (i.e., RAP teams), will be folded into the FRMAC.

12. Determine how FRMAC monitors can pass through road blocks into evacuated areas in order to perform monitoring duties. 
13. Identify local and/or facility personnel, familiar with the area, who are available to drive FRMAC monitoring vehicles.

\section{G.2 Priorities}

The initial FRMAC Monitoring and Sampling Plan will reflect LFA and state(s) requirements and should include the following general priorities:

1. Support for the LFA and the state(s).

2. If a large, unmonitored release is ongoing or is projected, determine if inhalation may be a major source of risk (i.e., are radioiodines present).

3. Monitor close to the evacuated areas where people are located.

4. After deposition, determine isotopic ratios.

5. Identify areas that have not been evacuated but where early health effects are possible (greater than 100 rem in four days; i.e., 1 rem/h)

6. Identify areas that have not been evacuated but where the EPA Early Phase Protective Action Guide (PAG) may be exceeded (greater than $1 \mathrm{rem}$ in four days; i.e., approximately $10 \mathrm{mrem} / \mathrm{h}$ ).

7. Provide a measure of the validity for the dispersion models in use.

8. Establish air sampling stations to measure resuspension and future plume releases.

9. Monitor institutions, facilities, or residences located in the evacuated areas which were not evacuated or where people must reenter in the near future.

10. Look for hot spots and characterize the off-site area.

11. Monitor and document areas for possible return of residents.

12. Sample surface drinking water supplies and open-air water treatment facilities.

\section{G.3 Strategies}

To accomplish the priorities, the following strategies should be considered.

1. Monitoring Aircraft

a. If aircraft are on-scene prior to plume release (helicopters plus fixed-wing aircraft), the following actions will be performed:

- Maintain the fixed-wing aircraft in a readiness mode at a nearby airport.

- To detect an unmonitored release, periodically fly a helicopter, at a safe distance, in a fixed, repeatable pattern above the reactor site.

- Upon detection of a significant plume release, replace the helicopter with the fixed-wing aircraft. The fixed-wing aircraft will be used as follows:

1) Track the plume.

2) Determine plume height, size, and direction.

3) Attempt to identify the major isotopes including the radioiodines.

4) Transect and sample the plume for source term determination, if necessary. 
b. By tracking the plume with aircraft, invaluable information is obtained for positioning monitoring personnel downwind and for identifying areas for possible initiation of protective actions.

2. Plume Release

a. If possible prior to plume release, place gamma monitors with telemetry, air samplers, and thermoluminescence dosimeters (TLDs) (all three at the same location) at representative locations between the fence line and populated areas. Emphasis should be given to the prevailing wind direction if it exists.

b. Place gamma monitors, air samplers, and TLDs at representative populated areas.

c. Based on information received from the monitoring aircraft and the meteorological conditions, deploy monitoring teams to travel roads in the vicinity of the incident site looking for the plume.

d. Each team should be equipped with plume sampling and radioiodine analysis capability. Teams should traverse assigned areas until contact is made with the plume. The teams should proceed as follows:

1) Notify the FRMAC when the plume is detected.

2) Proceed through the plume until maximum radiation is detected (always being aware of radiation turn-back levels).

3) Stop, exit the vehicle, and make beta/gamma open and closed window measurements at waist height and at ground level.

4) If the waist-height, open beta window measurement $(\beta+\gamma)$ is significantly greater than the waist-height, closed beta window measurement $(\gamma)$, the monitor is probably in the plume and should collect a five-minute, high-volume air sample using a filter medium and a silver zeolite or similarly treated charcoal cartridge.

5) Proceed through the plume noting when the plume is exited.

6) In a background area, analyze the charcoal cartridge for the presence of radioiodines.

7) Report the radioiodine results to the FRMAC.

3. Deposition Measurements by Aircraft

Upon arriving at the location of a radiological emergency where deposition has occurred, the radiological monitoring aircraft will fly a serpentine pattern traversing the predominant plume footprint and a circle with a radius of 10 miles around the emergency site. The mission for this initial flight is to determine the following:

a. Direction and approximate exposure rates along the deposition center line.

b. Outline of contamination footprint.

c. Major isotopes.

Following the initial flight, detailed radioactive deposition mapping is performed. The flight plan is dependent on radiological conditions, weather, terrain, and priorities. Depending on the magnitude of the release, the size of the deposition footprint, and monitoring requirements, the aircraft's altitude and the distance between the parallel flight lines will vary. Normally, the helicopter flies at an approximate altitude of 150 feet and a speed of $70 \mathrm{knots}$. Parallel flight lines are separated by approximately 250 feet. Flying at an altitude of 150 feet provides a monitoring window on the ground of about 300 feet in width. In this manner, the helicopter can map the ground deposition at a rate of approximately four square miles per hour. 
Products available from aerial mapping include:

- Isodose and exposure contours calculated to 1 meter above the ground.

- Soil deposition determinations of specific radionuclides.

- Total activity inventories of radionuclides of interest.

- Gamma-ray energy spectra.

The monitoring aircraft provides a very rapid and exhaustive method for radiologically mapping an area, and it should be used to complement the monitoring performed by field teams. In concert with the principle of ALARA (as low as reasonably achievable), the aircraft should be utilized instead of ground field teams for monitoring in the more highly contaminated areas. Also, the aircraft can be used to monitor where road access is limited. Sufficient overlap between the monitoring aircraft and the field monitoring activities is required to estimate the comparability of the radiological data.

4. Monitoring Where People Reside

Based on the aerial monitoring and meteorological data, initiate monitoring in the downwind direction from the plume footprint. Monitor where people are residing in the nonevacuated areas. Continue monitoring for 360 degrees. Attempt to monitor along the edge of the inhabited zones closest to the evacuated areas. Place representative, continuous particulate and reactive gas air samplers and TLDs in these close-in inhabited areas to measure resuspension, integrated exposure, and possible future plume releases. The actual placement of the samplers should be determined by the number of samplers available, population distribution, and local windrose. The following types of facilities usually have electrical power available and are "good" places to locate air samplers:

- Fire and police stations.

- County and state road maintenance facilities.

- Schools and public park facilities.

- City, county, and state municipal buildings.

- Hospitals.

If none of these facilities are available, attempt to locate the samplers at service stations, convenience stores, or residences. As a last resort, use the portable generators to supply the electrical power for the samplers.

5. Deposition

Identify isotopic mix and verify deposition models by taking appropriate radiation measurements using roadways and the monitoring aircraft to traverse the predicted footprint. The chosen roadways and flight paths should intersect a representative number of predicted radiation contours. Depending on the radiological release, if applicable, in situ gamma spectrometry systems are the preferred field-team instrument to be used with an exposure rate meter. Also as a rule-ofthumb, soil and vegetation samples should be collected at every order-of-magnitude change in measured radiation levels.

6. Monitoring Institutions, Facilities, and Residences Located in the Evacuated Areas Which Were Not Evacuated or Where People Must Reenter in the Near Future

The monitoring of these areas must be coordinated with state and/or local officials. When approaching nonevacuated residences, monitoring teams should be accompanied by local uniformed police or firemen. It is necessary to monitor the exteriors of the structures as well as the 
interiors. Interior monitoring will include the acquisition of swipes from representative surfaces. Environmental TLDs should be placed inside and outside of each occupied structure. Representative individuals at each location should be assigned a TLD to wear. If available, gammarate recorders should be placed inside the structures. The appropriateness of locating particulate and reactive gas air samplers at these stay-in locations should be determined. A brochure describing basic facts about radioactivity and exposure reduction techniques for inhabited structures should be distributed.

7. Characterization

For monitoring and sampling activities, the MD will use the Nuclear Regulatory Commission (NRC) sector divisions of the off-site area (16-22.5-degree sectors). If the FRMAC response is to other than an NRC-related incident, the MD can create 22.5-degree sector/distance maps oriented about the incident site by using FRMAC geographical information system capabilities. To characterize the area and to identify hot spots, at least one monitoring team should be assigned to each sector. If practical, monitoring activities should be initiated at a distance well beyond the deposition footprint and moved in toward the incident center. As the monitoring progresses, a serpentine pattern will be followed throughout the sector as closely as safe vehicle travel allows. The sites where representative radiation measurements are taken should include all preestablished state, local, and facility monitoring locations. Soil and vegetation samples should be collected at each order-of-magnitude change in the radiation field measurements or as directed. At representative locations, including within the evacuated areas, a continuous air sampler and an environmental TLD should be positioned. Together, they will provide a measure of resuspension and integrated radiation exposure at that location. These will complement those placed near the evacuated/inhabited areas.

\section{Drinking Water}

In coordination with state and/or local officials, drinking water samples should be collected from surface supplies and open-air water treatment facilities located in the affected areas.

9. Farms, Dairies, and Food Processing Plants

The monitoring and sampling of farms, dairies, and food processing plants will, in all likelihood, be conducted at the request of state or local officials. If no priorities or requests are received, the FRMAC should consider the following:

- Farms and dairies within the deposition footprint will receive last priority for MD resources (contamination is ensured because of their location and, therefore, their products are not immediately marketable).

- Farms outside of the deposition footprint will be monitored in order of the perishability of crops.

- Milk, food, and animal feed processing facilities outside of the evacuated area will be monitored and sampled in order of their "importance."

\section{G.4 Sampling Frequency}

1. Air Sampling

Particulate and reactive gas samples and whole air samples for noble gas analysis are exchanged daily. In most situations if samplers are in operation when a plume release occurs, the samples will be changed out following plume passage. 


\section{TLDS}

The lower levels of detection for personnel and area TLDs are approximately 10 mrem and 10 $m R$, respectively. The TLDs should be deployed for a sufficient length of time so that meaningful data that meets FRMAC objectives are produced.

3. Milk Sampling

Following a single release containing radioiodine, the radioiodine will begin to appear in the milk of exposed cows and goats in three to four hours. The radioiodine concentration will attain a maximum in approximately three days. For these reasons, milk sampling should begin the day after the plume passes. If milk from a particular dairy is to be characterized, sampling should begin with the first milking after the plume passes and continue daily. When the milk is collected, samples of the animals' feed and water should also be collected.

Note: From the same exposure, goat's milk will have radioiodine concentrations four times greater than cow's milk.

\section{Water Sampling}

Community surface drinking water supplies and open-air water treatment facilities located within the deposition footprint should be sampled following passage of the plum and resampled daily. Daily sampling should continue until useability of the water is determined (i.e., does it meet drinking water standards or is it a non-flowing body of water sufficiently contaminated that it cannot be used as a drinking water supply for some period of time).

Community surface drinking water supplies located outside of the deposition footprint but in the proximity should be sampled daily for a minimum of three days or until acceptable levels are achieved.

Sediment samples will be collected from surface drinking water supplies located within the deposition footprint and resampled as required.

5. Note on Collecting Samples

Care should be exercised in collecting environmental samples. The radioanalytical laboratories can be easily inundated. A sufficient number of samples must be collected to characterize the environment and to satisfy monitoring requirements, but the collection of samples should be performed prudently. 


\section{APPENDIX H}

\section{ACRONYMS}

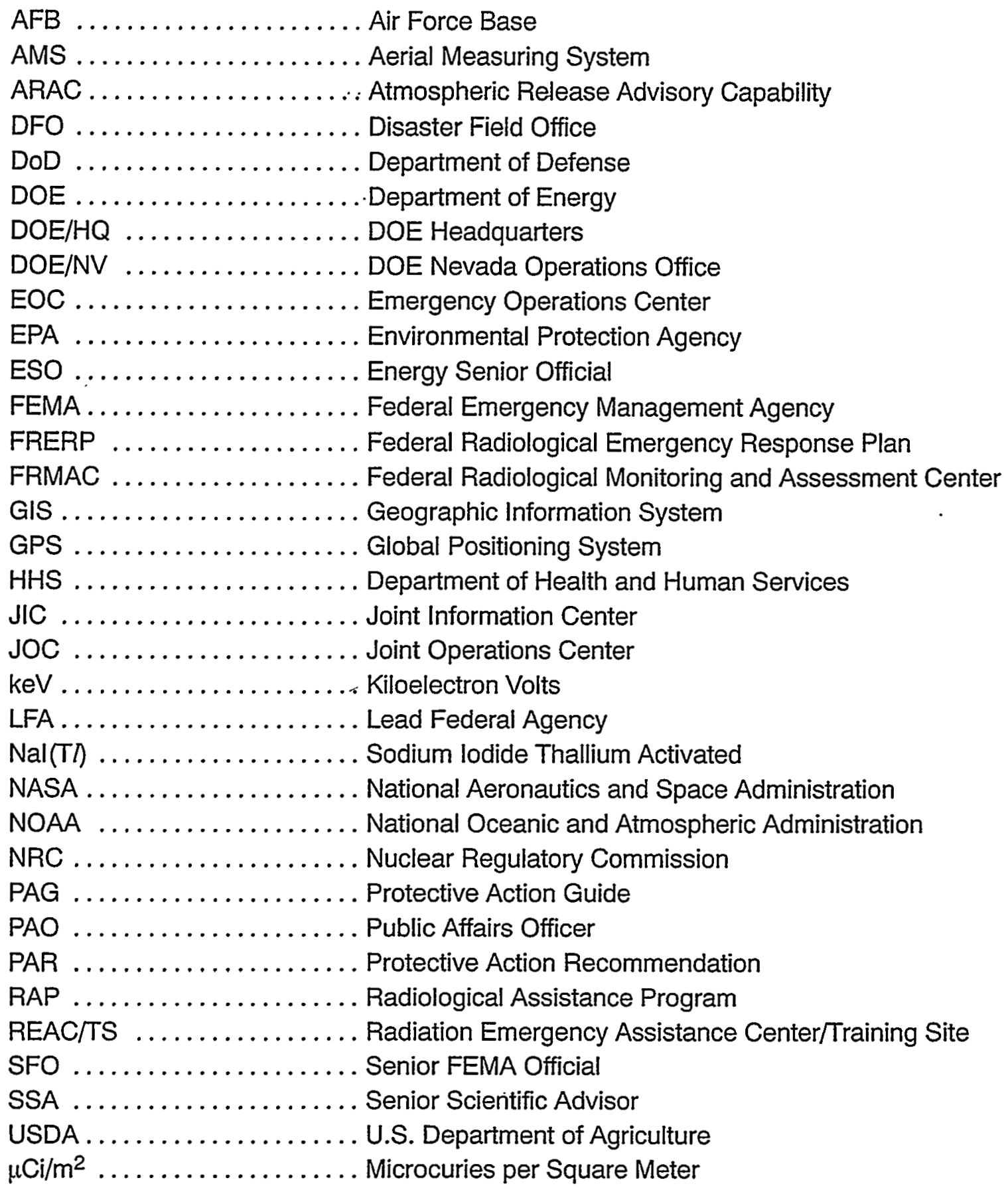

